\title{
Molecular evidence that the Channel Islands populations of the orange-crowned warbler (Oreothlypis celata; Aves: Passeriformes: Parulidae) represent a distinct evolutionary lineage
}

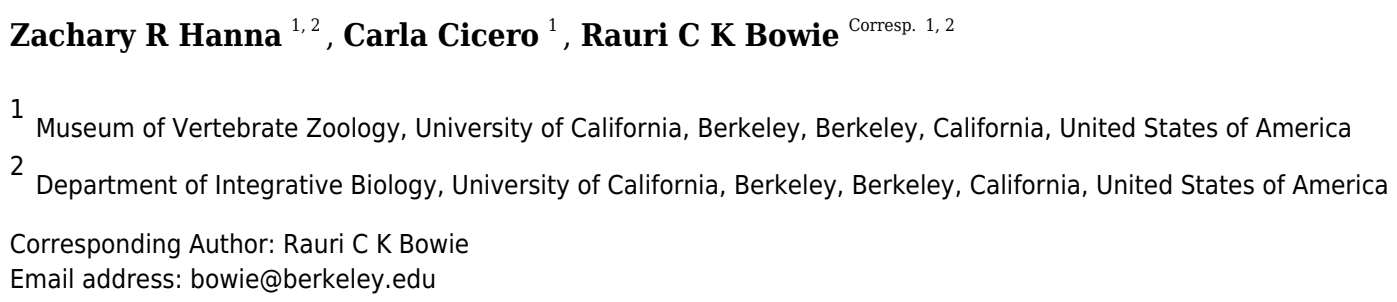

We used molecular data to assess the degree of genetic divergence across the breeding range of the orange-crowned warbler (Oreothlypis celata) in western North America with particular focus on characterizing the divergence between $O$. celata populations on the mainland of southern California and on the Channel Islands. We obtained sequences of the mitochondrial gene ND2 and genotypes at ten microsatellite data for 192 O. celata from populations spanning all four recognized subspecies. We recovered shallow but significant levels of divergence among $O$. celata populations across the species range. Our results suggest that island isolation, subspecies (delineation by morphology, ecological and lifehistory characteristics), and isolation-by-distance, in that order, are the likely best explanatory variables of the geographic structure detected across the range of $O$. celata. Populations on the Channel Islands were genetically divergent from those on the mainland. We found evidence for greater gene flow from the Channel Islands population to mainland southern California than from the mainland to the islands. We discuss these data in the context of differentiation in phenotypic and ecological characters. 
1 Molecular evidence that the Channel Islands populations of the orange-crowned warbler

2 (Oreothlypis celata; Aves: Passeriformes: Parulidae) represent a distinct evolutionary lineage

3 Zachary R. Hanna, ${ }^{1,2}$ Carla Cicero, ${ }^{1}$ Rauri C. K. Bowie,,${ }^{1,2 *}$

4

$5{ }^{1}$ Museum of Vertebrate Zoology, University of California, Berkeley, Berkeley, California,

6 United States of America

72 Department of Integrative Biology, University of California, Berkeley, Berkeley, California,

8 United States of America

$9 *$ Corresponding author

10 Rauri Bowie

11 bowie@,berkeley.edu

\section{Abstract}

14 We used molecular data to assess the degree of genetic divergence across the breeding range of

15 the orange-crowned warbler (Oreothlypis celata) in western North America with particular focus

16 on characterizing the divergence between $O$. celata populations on the mainland of southern

17 California and on the Channel Islands. We obtained sequences of the mitochondrial gene ND2

18 and genotypes at ten microsatellite data for 192 O. celata from populations spanning all four

19 recognized subspecies. We recovered shallow but significant levels of divergence among $O$.

20 celata populations across the species range. Our results suggest that island isolation, subspecies

21 (delineation by morphology, ecological and life-history characteristics), and isolation-by-

22 distance, in that order, are the likely best explanatory variables of the geographic structure

23 detected across the range of $O$. celata. Populations on the Channel Islands were genetically 
24 divergent from those on the mainland. We found evidence for greater gene flow from the 25 Channel Islands population to mainland southern California than from the mainland to the 26 islands. We discuss these data in the context of differentiation in phenotypic and ecological 27 characters. 


\section{Introduction}

Oceanic islands have served as a natural laboratory for evolutionary studies for decades

31 (Crawford, 2012). Patterns of phenotypic and genetic divergence on islands with varying degrees

32 of isolation shed light on the processes of adaptation and speciation (Losos \& Ricklefs, 2009;

33 Greenberg \& Danner, 2013) and provide data for evaluating traits that promote biodiversity

34 (Lomolino, 2005; Gunderson, Mahler \& Leal, 2018). Furthermore, comparisons of island taxa

35 and their mainland counterparts are fundamental to assessing the taxonomic status of island

36 endemics, many of which are of conservation concern (Wilson et al., 2009).

The California Channel Islands are well-known for their endemic or near endemic species and subspecies of birds (Johnson, 1972; Jones \& Diamond, 1976). Of the forty-one native land bird species found on these islands, thirteen (32\%) show phenotypic differentiation between the islands and mainland (Johnson, 1972). The islands are divided into two groups that differ geologically and biologically: the northern islands (San Miguel, Santa Rosa, Santa Cruz, and Anacapa) and the southern islands (San Nicolas, Santa Barbara, Santa Catalina, and San Clemente). Together, they extend for $260 \mathrm{~km}$ off the coast of southern California and range between 20 and $98 \mathrm{~km}$ from the mainland (Schoenherr, Feldmeth \& Emerson, 1999). Patterns and processes of avian (especially passerine) diversification on the Channel Islands have been a topic of interest among ornithologists for decades (Diamond, 1969; Johnson, 1972; Lynch \& Johnson, 1974; Greenberg \& Danner, 2013). Apart from the following, few Channel Islands bird taxa have been the subject of published genetic studies: Aphelocoma californica and A. insularis (Delaney, Zafar \& Wayne, 2008); Melospiza melodia (Wilson et al., 2009); Lanius ludovicianus, (Mundy, Winchell \& Woodruff, 1997; Caballero

50 \& Ashley, 2011); Eremophila alpestris (Mason et al., 2014); and Artemisiospiza belli (Karin et al., 51 2018). Overall, these studies have shown that the Channel Islands harbor genetic distinctiveness in 
52 avian populations and that levels of divergence and gene flow between the islands and mainland vary

53 among taxa.

54 The orange-crowned warbler (Oreothlypis celata) is currently divided into four

55 subspecies that differ in plumage color (Figures S1 and S2), size, molt patterns, habitat, song,

56 and timing of migration and breeding (Foster, 1967; Dunn \& Garrett, 1997; Gilbert, Sogge \&

57 Van Riper III, 2010). Oreothlypis celata celata (Say, 1823) breeds primarily in low, deciduous

58 shrub-dominated thickets in northern North America, including most of Alaska through eastern

59 Canada. Oreothlypis celata lutescens (Ridgway, 1872) prefers to nest in the dense riparian-

60 chaparral ecotone with vertical structure provided by oaks or conifers along the Pacific coast

61 from southeastern Alaska through California (Dunn \& Garrett, 1997). Oreothlypis celata sordida

62 (Townsend, 1890) nests in scrub and woodland on all eight California Channel Islands as well as

63 on the Islas Coronado and Islas de Todos Santos off the northwestern coast of Baja California,

64 and in restricted areas on the coast of mainland southern California (Dunn \& Garrett, 1997;

65 Schoenherr, Feldmeth \& Emerson, 1999). This subspecies is the only one that predominantly

66 nests off the ground on the mainland (Gilbert, Sogge \& Van Riper III, 2010). Oreothlypis celata

67 orestera (Oberholser, 1905) nests in dense riparian areas and, at higher elevations, in stands of

68 aspen groves in the Rocky Mountains from northern British Columbia through southern New

69 Mexico and in some mountain ranges within the western deserts of North America (Dunn \&

70 Garrett, 1997).

71 Analyzing the geographic differentiation and distribution patterns of Channel Island

72 birds, Johnson (1972) found evidence of both single and multiple colonization events, depending

73 on the particular taxon. For Oreothlypis celata, he hypothesized that the insular O. c. sordida

74 originated from a single colonization from the mainland to the northern Channel Islands,

75 followed by differentiation and subsequent dispersal among the islands and recolonization of the 
mainland in areas that were locally unsuitable for $O$. c. lutescens. He also hypothesized that $O$. $c$. sordida is more closely related to Rocky Mountain $O$. c. orestera populations than to Pacific coast $O$. c. lutescens populations, suggesting a relictual pattern of evolution and distribution. In the only published genetic study of Oreothlypis celata, Bull et al. (2010) used mitochondrial DNA (mtDNA) and microsatellite data to assess the relationships between northwestern North American populations of Oreothlypis celata celata and O. c. lutescens on Haida Gwaii, Canada. They found low, but statistically significant, differentiation between populations, suggesting recent divergence. They also found a pattern consistent with isolationby-distance. However, because Bull et al. (2010) did not include the other two O. celata subspecies (O. c. orestera and O. c. sordida) in their analyses, their data do not provide insight into broader patterns and processes of differentiation across the species, including between Channel Islands and mainland populations.

In order to analyze broad-scale divergences among populations, we sampled mitochondrial and nuclear genetic data from all four subspecies of Oreothlypis celata. We assessed the relationship between Channel Island and mainland southern California populations and determined the relative rates of migration between these populations to test Johnson's (1972) hypotheses about the origin and differentiation of $O$. celata on the Channel Islands. We discuss these data in the context of what is known about avian differentiation on the islands.

\section{Materials and methods}

\section{Population sampling}

We obtained blood and/or frozen tissue samples from 192 Oreothlypis celata individuals collected between 1983 and 2009 (Table S1) from western North America representing each of the four subspecies (Table S1 and Figure 1). To control for post-breeding dispersal, we used only 
99 samples collected during the breeding months of early April through July (Gilbert, Sogge \& Van

100 Riper III, 2010). We also obtained frozen tissue samples from two Nashville warblers

101 (Oreothlypis ruficapilla) to use as outgroups in our analyses. We obtained samples from museum

102 tissue collections (Table S1) and collected samples under California Department of Fish and

103 Game scientific collecting permit numbers SC-458 and SC-10109, U.S. Fish and Wildlife

104 Service permit number MB153526, and with permission from the UC Berkeley Animal Care and 105 Use Committee under Animal Use Protocols R285 and R317.

106 We examined populations at several hierarchical levels. First, we analyzed the data using

107 all of the samples without a priori groupings. When these initial analyses revealed little spatial

108 structure in the genetic data, we grouped the samples into eight populations (Figure 1) based on

109 their geographic proximity. This enabled us to explore the extent to which variation across

110 ecosystem boundaries (geography) and present taxonomy (subspecies) are reflected in the

111 genetic data. To explore the importance of geographic variation, we grouped the samples on

112 either side of two separate geographic divisions: northern versus southern (populations 1-3 and

113 4-8, respectively, in Figure 1) and coastal versus interior (populations 2, 6-8 and 1, 3-5,

114 respectively, in Figure 1). Our division between the northern and southern samples near the

115 Pacific Coast fell at the southern limit of the Cascade Range in northern California. In the

116 interior, we divided northern from southern samples between the Canadian Rocky Mountains

117 and the Southern Rocky Mountains at the northern Idaho Clearwater River drainage. These

118 landmarks are ecologically significant as they mark the southern extents of cedar-hemlock forest

119 ecosystems (Brunsfeld et al., 2001) and have been hypothesized by many as sites of lineage

120 contact in various taxa (Soltis et al., 1997; Swenson \& Howard, 2005; Burg et al., 2006). We

121 divided coastal from interior samples by designating as interior all areas east of the Alaska 
122 Range, Coast Mountains, the Cascades, and the Sierra Nevada, as splits between coastal and

123 interior populations have been hypothesized in other warbler taxa (Bermingham et al., 1992).

124 Finally, we grouped samples based on the four existing subspecific designations. We utilized

125 each of these four separate sample groupings in subsequent analyses.

126 Laboratory procedures

127 We extracted DNA from blood or frozen tissues using a DNeasy Blood \& Tissue Kit

128 (Qiagen, Hilden, Germany) following the Qiagen protocol for animal tissues. We sequenced the

129 mitochondrial genes NADH subunit 2 (ND2) and ATP Synthase subunit 6 (ATPO), both of which

130 are commonly used in avian phylogeographic studies. We amplified a 1041 base pair (bp)

131 fragment of the ND2 gene using the polymerase chain reaction (PCR) with primers L5204 and

132 H6312 (Sorenson et al., 1999). PCR reactions $(10 \mu \mathrm{L})$ contained 1X PCR Buffer (10 mM Tris-

$\left.133 \mathrm{HCl}, 1.5 \mathrm{mM} \mathrm{MgCl}_{2}, 50 \mathrm{mM} \mathrm{KCl}, \mathrm{pH} 8.3\right), 0.6 \mu \mathrm{M}$ of each primer, $200 \mu \mathrm{M}$ of each dNTP, $0.6 \mathrm{U}$

134 of Taq and approximately 5-10 ng of genomic DNA. The PCR profile included an initial

135 denaturation at $94^{\circ} \mathrm{C}$ for $2 \mathrm{~min}$; followed by 35 cycles of denaturation at $94^{\circ} \mathrm{C}$ for $30 \mathrm{~s}$, annealing

136 at $53^{\circ} \mathrm{C}$ for $30 \mathrm{~s}$, and extension at $72^{\circ} \mathrm{C}$ for $1 \mathrm{~min}$; with a final extension at $72^{\circ} \mathrm{C}$ for $10 \mathrm{~min}$. We

137 amplified a 704 bp fragment of the ATP6 gene by PCR using the primers a8PWL and C03HMH

138 (http://nmg.si.edu/bermlab.htm). The PCR profile followed that for the ND2 gene, except for

139 annealing at $54^{\circ} \mathrm{C}$ and extension for $45 \mathrm{~s}$ during the 35 cycle phase before the final extension.

140 We purified the PCR products using Exonuclease I and Shrimp Alkaline Phosphatase

141 (ExoSAP-IT ${ }^{\mathrm{TM}}$, Applied Biosystems, Waltham, Massachusetts, U.S.A.) and sequenced the

142 purified products using Big Dye terminator chemistry v. 3.1 (Applied Biosystems) and an AB

143 PRISM 3730 DNA Analyzer (Applied Biosystems). We analyzed only samples for which we

144 obtained sequences of both the forward and reverse DNA strands. We aligned complementary 
145 DNA strands, edited all sequences, detected stop codons, and aligned consensus sequences using

146 Sequencher version 4.7 (Gene Codes Corporation, Ann Arbor, Michigan, U.S.A.). After

147 obtaining $704 \mathrm{bp}$ of ATP6 for 106 individuals, we detected the presence of a pseudogene in

148 sequences and thus eliminated the ATP6 gene from further analyses.

149 We used ten polymorphic microsatellite markers (Vce34, Vce50, Vce70, Vce102,

150 Vce103, Vce109, Vce116, Vce128, Vce167, and Vce179) developed for O. celata (Bowie et al.,

151 2017). All ten loci were tetranucleotide repeats and three of them had imperfect core repeats. We

152 amplified these microsatellites using PCR in $10 \mu \mathrm{L}$ reactions containing: 1x PCR Buffer (10 mM

153 Tris- $\left.\mathrm{HCl}, 1.5 \mathrm{mM} \mathrm{MgCl}_{2}, 50 \mathrm{mM} \mathrm{KCl}, \mathrm{pH} 8.3\right), 0.6 \mu \mathrm{M}$ of each primer, $200 \mu \mathrm{M}$ of each dNTP,

154 0.6 U of Taq and approximately 5-10 ng of genomic DNA. The PCR conditions included one

155 denaturation cycle at $94^{\circ} \mathrm{C}$ for 2 min and 30 cycles consisting of $15 \mathrm{~s}$ of denaturation at $94^{\circ} \mathrm{C}, 15$

$156 \mathrm{~s}$ of annealing at $50-55^{\circ} \mathrm{C}$, and $15 \mathrm{~s}$ of extension at $72^{\circ} \mathrm{C}$. We used T4 DNA polymerase (New

157 England Biolabs, Ipswich, Massachusetts, U.S.A.) treatment to clean the PCR products of the

158 Vce34, Vce50, Vce102, Vce103, Vce128, and Vce179 markers (Ginot et al., 1996). We mixed

159 the samples with formamide and GS-500 LIZ size standard (Applied Biosystems) and analyzed

160 them using an AB PRISM 3730 DNA Analyzer. We conducted allele binning and genotyping

161 using Genemapper version 4.0 (Applied Biosystems).

162 Mitochondrial DNA analyses

163 We analyzed the ND2 sequences using maximum likelihood (ML), neighbor-joining

164 (NJ), and maximum parsimony (MP) algorithms. We used RAxML BlackBox (Stamatakis,

165 Hoover \& Rougemont, 2008) to construct an ML tree with 100 bootstrap replicates and PAUP*

166 version $4.0 \mathrm{~b} 10$ (Swofford, 2003) to construct NJ and MP trees. Preliminary analyses of the

167 mtDNA data using NJ, ML, and MP algorithms were not informative and intraspecific datasets 
168 often do not comply with the assumptions of MP and ML algorithms (Posada \& Crandall, 2001).

169 Therefore, we did not further explore tree-building methods that assume bifurcation of lineages

170 by default and instead focused on the population genetics approaches described hereafter.

171 We generated a statistical parsimony network using TCS version 1.01 (Clement, Posada

$172 \&$ Crandall, 2000) to visualize relationships among haplotypes and to analyze phylogeographic

173 structure. In addition, we used analysis of molecular variance (AMOVA) in Arlequin version 3.1

174 (Excoffier, Smouse \& Quattro, 1992; Excoffier, Laval \& Schneider, 2007) to calculate the

175 proportion of total mtDNA genetic variation explained by population groupings. The AMOVA

176 provided estimates of overall $F_{\mathrm{ST}}$ and its analogue, $\Phi_{\mathrm{ST}}$ (calculated using the Tamura-Nei model

177 with a 0.05 gamma correction), using a non-parametric permutation approach to determine

178 significance levels (Excoffier, Smouse \& Quattro, 1992). We used Arlequin version 3.1 to

179 examine genetic structure among population subdivisions by calculating pairwise $F_{\mathrm{ST}}$ and $\Phi_{\mathrm{ST}}$

180 statistics (10,000 permutations) and applying sequential Bonferroni corrections when evaluating

181 significance (Rice, 1989). We also used Arlequin version 3.1 to estimate haplotype diversity $(h)$

182 and nucleotide diversity $(\pi)$ (Nei, 1987), to calculate pairwise mismatch distributions for

183 populations (Sum of Squared deviations and Harpending's Raggedness index calculated to test

184 goodness of fit; 10,000 bootstrap replicates), and to run two tests of selective neutrality, Tajima's

185 D (Tajima, 1989) and Fu's $F(F u, 1997)$ tests.

186 We performed a spatial analysis of molecular variance (SAMOVA) using SAMOVA 1.0

187 (Dupanloup, Schneider \& Excoffier, 2002) to assess the geographic arrangement of genetic

188 structure. Unlike an AMOVA, this method does not require an a priori definition of populations.

189 Instead, it uses sequence and geographic coordinate data (Lambert projection) to maximize the

190 proportion of total genetic variation among populations (Dupanloup, Schneider \& Excoffier, 
191 2002). We identified the most likely partitioning of the samples by running SAMOVA 1.0

192 repeatedly with 2 to 20 groups and looking for the division assemblage with a maximized $F_{\mathrm{CT}}$

193 (Dupanloup, Schneider \& Excoffier, 2002).

194 Microsatellite analyses

195 We used Arlequin version 3.1 (Excoffier, Laval \& Schneider, 2007) to calculate observed

$196\left(\mathrm{H}_{\mathrm{O}}\right)$ and expected $\left(\mathrm{H}_{\mathrm{E}}\right)$ heterozygosity values. We tested for Hardy-Weinberg equilibrium

197 (HWE) and heterozygote deficiency using Genepop version 4.0.10 (10,000 dememorization

198 steps, 1,000 batches, 10,000 iterations) (Raymond \& Rousset, 1995; Rousset, 2008). In addition,

199 we tested the microsatellite genotypes in each population and at each locus for linkage

200 equilibrium using Genepop version 4.0.10 (10,000 dememorization steps, 1,000 batches, 10,000

201 iterations) (Raymond \& Rousset, 1995), applying sequential Bonferroni corrections when

202 evaluating significance (Rice, 1989). We examined null allele presence using Micro-Checker

203 version 2.2.3 (Van Oosterhout et al., 2004) and used FSTAT version 2.9.3.2 (Goudet, 1995,

204 2001) to estimate allelic richness $\left(R_{s}\right)$, which controls for sample size when comparing the

205 number of alleles among populations (Leberg, 2002).

206 We tested the proportion of total genetic variance explained by population groupings by

207 performing an AMOVA (Excoffier, Smouse \& Quattro, 1992) in Arlequin version 3.1, which

208 provided estimates of overall $F_{\mathrm{ST}}$. We calculated the significance levels for the AMOVA using a

209 non-parametric permutation approach (10,000 permutations) (Excoffier, Smouse \& Quattro,

210 1992). We examined genetic structure among population subdivisions by calculating pairwise

$211 F_{\mathrm{ST}}$ values using Arlequin version 3.1 (10,000 permutations) and pairwise $R_{\mathrm{ST}}$ values using

212 RSTCALC version 2.2 (Goodman, 1997), applying sequential Bonferroni corrections for

213 multiple simultaneous comparisons when evaluating significance (Rice, 1989).

Peer] reviewing PDF | (2018:09:31580:2:0:NEW 27 Jun 2019) 
215 distances (isolation-by-distance) among all individuals sampled by conducting a Mantel test

216 using GenAlEx version 6.1 (Peakall \& Smouse, 2006, 2012). We also used GenAlEx version 6.1

217 to run a principal coordinates analysis (PCA) in order to examine the organization of the genetic 218 structure.

219 In a further effort to detect spatial organization in our sample assemblage, we analyzed 220 our dataset of ten microsatellite loci using Structure version 2.3.4 (Pritchard, Stephens \& 221 Donnelly, 2000; Falush, Stephens \& Pritchard, 2003; Hubisz et al., 2009; Pritchard, Falush \& 222 Hubisz, 2012). This method uses Bayesian clustering to examine genetic frequencies across loci 223 and attempts to identify the number of clusters $(K)$ based on the likelihood values for varying $K$ 224 values. We performed preliminary analyses without providing any information concerning 225 population designations. After these initial analyses, we then designated eight populations in the 226 input and used this information as a prior (LOCPRIOR) (Hubisz et al., 2009) in further analyses 227 to improve population discrimination. We implemented the analyses using the admixture model 228 with correlated allele frequencies (Falush, Stephens \& Pritchard, 2003), examined $K=1-20$, 229 executed a 100,000 MCMC iteration burn-in, and then performed 1,000,000 subsequent MCMC 230 iterations. We replicated the simulation at each $K$ twenty times. To assist in identifying the 231 optimal $K$, we used Structure Harvester version 0.6.94 (Earl \& vonHoldt, 2012; Earl, 2014), 232 which uses the Evanno et al. (2005) method to identify the number of clusters. We ran Structure 233 and Structure Harvester using StrAuto version 1.0 (Chhatre \& Emerson, 2017, 2018) with GNU

234 Parallel version 20141022 (Tange, 2011). To align clusters across the Structure runs, we ran 235 CLUMPP version 1.1.2 (Jakobsson \& Rosenberg, 2007) and then used a modified version of 
236 Distruct version 2.2 (Raj, Stephens \& Pritchard, 2014; Chhatre, 2016; Hanna, Cicero \& Bowie, 237 2018) to plot the clusters.

238 Based on the results of the Structure analysis described above, we ran two additional

239 Structure analyses to check for the presence of substructure. We first analyzed the Channel

240 Islands samples with the samples from Santa Cruz Island and Santa Catalina Island split into

241 separate populations. We used the parameters as detailed above, including the LOCPRIOR for

$242 K=1-10$. We then analyzed the seven remaining populations with the same parameters as above 243 for $K=1-20$.

244 In order to assess the relative rate of migration between the Channel Islands and mainland 245 southern California, we ran IMa2p version 58a0260 (Sethuraman \& Hey, 2015; Sethuraman, 246 2017). We input both the ND2 sequences and microsatellite genotypes and performed three 247 separate runs each with 15 chains, 1,000,000 burnin steps, and 2,000,000 further steps following 248 the burnin. We have provided further methodology details in ocwa-popgen version 1.0.0 on 249 GitHub (Hanna, Cicero \& Bowie, 2018).

250 Results

$251 m t D N A$ sequence variation

252 We obtained a complete $1041 \mathrm{bp}$ fragment of the mtDNA ND2 gene for 192 Oreothlypis 253 celata and two O. ruficapilla individuals; there were no missing data and no insertions, deletions, 254 or gaps. After merging identical sequences, we found 72 unique haplotypes (Table S1) with 81 255 variable sites. We found no evidence for selection $(P=0.702)$ between Oreothlypis celata 256 sequences and two sequences of the closely related O. ruficapilla (Lovette, Bermingham \& 257 Sheldon, 2002). 
258

259

260

261

262

263

264

265

266

267

268

269

270

271

272

273

274

275

276

277

278

279

280

mtDNA haplotype network

Examination of the statistical parsimony network revealed shared alleles, regardless of how we grouped samples into populations (Figures 2 and S3). The haplotypes clustered largely along a north-south geographic axis, but the majority of the Haida Gwaii Oreothlypis celata possessed haplotypes in the "southern" group. Three mutational differences separate the major haplotype clusters of the northern and southern $O$. celata with some outlier individuals falling into each grouping.

The Oreothlypis celata haplotypes from the Channel Islands clustered much more tightly than those from Haida Gwaii. We found four ND2 haplotypes among the Channel Islands $O . c$. sordida, but the majority of individuals shared a single haplotype; the three other Channel Islands haplotypes appeared only in one individual each (Figure 2). There was at most one mutational difference between the haplotype of a Channel Islands $O$. celata and the next Channel Islands haplotype. Although we found three singleton, private Channel Islands ND2 haplotypes, individuals from northern and southern California shared the most common Channel Islands haplotype. The Haida Gwaii samples, with eleven haplotypes, were more loosely clustered than the Channel Islands samples with a maximum of nine mutational steps between individuals (Figure S3).

When we identified samples by subspecies (Figure 3), we found no interior Oreothlypis celata orestera individuals that shared haplotypes with the Channel Islands O. c. sordida. We did, however, find $O$. c. orestera haplotypes that were one mutational step away from $O . c$. sordida haplotypes (Figure 3). The main cluster of O.c. lutescens haplotype diversity was separated from the O.c. sordida haplotype cluster by a haplotype more often found in $O$. c. orestera than in $O$. c. lutescens. The haplotypes did not appear to cluster across a coast-interior 
281 axis (Figure S3). However, with the exception of one Haida Gwaii haplotype, the island

282 populations of the Channel Islands and Haida Gwaii did not share haplotypes with any

283 individuals from interior populations.

\section{Population structure inferred from mtDNA}

285 Variability in mtDNA sequences differed among populations (Table 1). We found that

286 the Channel Islands population had the lowest nucleotide diversity $\left(0.2 \times 10^{-3}\right)$ of all eight

287 populations, whereas the northern California population had the highest $\left(3.7 \times 10^{-3}\right)$. The

288 nucleotide diversity of the Haida Gwaii population $\left(2.8 \times 10^{-3}\right)$ was substantially higher than that

289 of the Channel Islands populations and equaled that of the southern California population $(2.8 \times$

$\left.29010^{-3}\right)$. When grouped into northern and southern population clusters, the two groupings contained

291 almost exactly the same nucleotide diversities $\left(2.9 \times 10^{-3}\right.$ and $3.0 \times 10^{-3}$, respectively).

292

Although the statistical parsimony networks (Figures 2, 3, and S3) did not display

293 evidence of reciprocal monophyly among populations or subspecies, the AMOVA revealed

294 significant differentiation in haplotype frequencies for each of the four alternative groupings of

295 our samples. Overall $F_{\mathrm{ST}}$ estimates from our AMOVA analysis of $N D 2$ sequences were all highly

296 significant $(p<0.01)$ for samples grouped into: (1) northern and southern clusters (0.191); (2)

297 eight populations (0.202); (3) coastal and interior clusters (0.186); and (4) subspecies (0.195)..

298 Overall $\Phi_{\mathrm{ST}}$ estimates were greater than the $F_{\mathrm{ST}}$ estimates for the different population data sets,

299 and were also all highly significant with $p<0.01$ : (1) northern-southern (0.429); (2) eight-

300 population (0.365); (3) coastal-interior (0.254); and (4) subspecies $(0.299) .$. The pairwise

301 population $F_{\mathrm{ST}}$ values reflected patterns that were nearly congruent to the pairwise $\Phi_{\mathrm{ST}}$ estimates,

302 so we have chosen to present only the pairwise $\Phi_{\mathrm{ST}}$ estimates (Tables 2, 3 and 4). 
Pairwise population $F_{\mathrm{ST}}$ and $\Phi_{\mathrm{ST}}$ estimates ( 0.036 and 0.000 , respectively) between Santa

304 Cruz Island (northern Channel Islands) and Santa Catalina Island (southern Channel Islands)

305 were not significant. However, pairwise $\Phi_{\mathrm{ST}}$ estimates supported the collective Channel Islands

306 as a distinct population. Pairwise $\Phi_{\mathrm{ST}}$ values between the Channel Islands and every other

307 population were significant, ranging from 0.245 to 0.809 with the samples grouped into eight

308 populations (Table 2) and from 0.228 to 0.681 with the samples grouped into northern and

309 southern clusters (Table 3). With the samples grouped into eight populations, we estimated the

310 highest pairwise $\Phi_{\mathrm{ST}}$ values between the Channel Islands and the two northern, interior

311 populations (Fairbanks, 0.809; Northern Rocky Mountains, 0.754). Of all of the pairwise

312 comparisons involving the Channel Islands, we estimated the lowest $\Phi_{\mathrm{ST}}$ between the Channel

313 Islands and the northern and southern California populations (0.245 and 0.261, respectively).

314 Pairwise $\Phi_{\mathrm{ST}}$ estimates between Haida Gwaii and every other population within the set of

315 eight populations were significant, except for those between Haida Gwaii and the northern and

316 southern California populations. Of all of the Haida Gwaii pairwise comparisons, pairwise $\Phi_{\mathrm{ST}}$

317 was highest (0.564) between the Haida Gwaii and Channel Islands populations. The pairwise

$318 \Phi_{\mathrm{ST}}$ estimate was significant between the northern and southern populations $(0.479$; Table 3$)$, but

319 it was not as high as the estimate between the northern and Haida Gwaii populations (0.492). In

320 contrast, pairwise $\Phi_{\mathrm{ST}}$ was much lower between Haida Gwaii and the southern population

321 (0.094; Table 3).

322 With the samples grouped by subspecies (Table 4), we estimated significant pairwise $\Phi_{\text {ST }}$

323 between Oreothlypis c. sordida and all other subspecies, with the lowest values between $O . c$.

324 sordida and $O$. c. lutescens (0.232) and the highest between $O$. c. sordida and O. c. celata

325 (0.786). Oreothlypis c. lutescens and O.c. orestera had the lowest pairwise $\Phi_{\mathrm{ST}}$ value of all of 
326 the subspecies comparisons. All of the pairwise $\Phi_{\mathrm{ST}}$ estimates were significant when we grouped

327 the samples by subspecies (Table 4) and by coastal versus interior populations (Table S2).

328 SAMOVA

329 As we found with our maximum parsimony and maximum likelihood analyses, our

330 SAMOVA analyses indicated that deep genetic structure is not present in our mitochondrial

331 sequence data set. We never obtained a maximized $F_{\mathrm{CT}}$ with the SAMOVA analyses, so we

332 could not reject panmixia or obtain support for population structure greater than $K=1$. SAMOVA

333 is known to perform poorly in the presence of isolation-by-distance (Dupanloup, Schneider \&

334 Excoffier, 2002) and we recovered significant isolation-by-distance in the microsatellite data.

335 However, the trend was weak and likely did not greatly affect the SAMOVA analyses. Although

336 we never recovered a maximized $F_{\mathrm{CT}}$ with the SAMOVA analyses, we examined the groupings

337 created for $K=2-4$ to see whether the analyses recovered any divisions between northern,

338 southern, and island samples. These analyses partitioned the samples in general agreement with

339 our northern and southern sample groupings. For $K=2$, we recovered one group composed

340 entirely of northern samples. The second group included all of the southern, Channel Islands, and

341 Haida Gwaii samples as well as samples from five coastal and interior localities (in British

342 Columbia, Alberta, and Fairbanks) in our designated northern population. Grouping samples

343 with $K=3$ and $K=4$ created partitions within the northern and southern populations but were not

344 consistent with subspecies boundaries.

345 Mismatch distributions

346 Mismatch profiles that follow a Poisson distribution suggest population growth following

347 an event such as a range expansion (Rogers \& Harpending, 1992; Harpending et al., 1993).

348 Multimodal mismatch profiles can suggest a number of different population dynamic scenarios, 
349 such as constant size (Slatkin \& Hudson, 1991; Rogers \& Harpending, 1992; Harpending et al.,

350 1998), expanding fronts (Liebers, Helbig \& De Knijff, 2001), and geographic structuring

351 resulting from restricted gene flow (Marjoram \& Donnelly, 1994). All populations had negative

352 Tajima and Fu statistics and all were statistically significant with the exception of the Fairbanks

353 and Northern Rocky Mountains populations for Tajima's D and the southern California

354 population for Fu's $F$ (Table 1). Harpending's Raggedness indices were not statistically

355 significant for mismatch distributions in any of the populations, indicating that we could not

356 reject a population expansion hypothesis (Table 1). The northern, southern, and Channel Islands

357 populations displayed mismatch profiles following a Poisson distribution, suggesting recent

358 population growth (Figure 4). With the samples grouped into eight populations, we observed

359 mismatch profiles with a Poisson distribution in all populations except the Fairbanks and Haida

360 Gwaii populations, both of which appeared to have multimodal mismatch profiles (Figure 4).

361 Population structure inferred from microsatellite data

362 We successfully obtained genotypes for 192 Oreothlypis celata individuals at ten

363 microsatellite loci with no missing data apart from three individuals for which we were unable to

364 genotype a subset of the loci (Tables 5, S3, and S4). We found no evidence for null alleles in any

365 microsatellite locus in any population. In addition, there was no evidence for linkage

366 disequilibrium in the northern, southern, Channel Islands, or Haida Gwaii populations; no

367 disequilibrium tests were significant after we applied Bonferroni corrections. We did not observe

368 deviation of observed heterozygosity from Hardy-Weinberg equilibrium (HWE) expectations

369 repeatedly across loci in any of the populations resulting from our various methods of sample

370 grouping. Observed heterozygosity at all ten loci did not differ from that expected under HWE

371 for the northern, southern, Channel Island, and Haida Gwaii population set. However, locus 
372 Vce34 was out of HWE in the Fairbanks population, locus Vce167 was out of HWE in the

373 interior population, and locus Vce34 was out of HWE in the O.c. celata population.

374 The overall $F_{\mathrm{ST}}$ estimates from our analysis of microsatellite genotypes for the northern-

375 southern, eight-population, coastal-interior, and subspecies population sets $(0.017,0.022,0.016$,

3760.020 , respectively) were all highly significant $(p<0.001)$. Overall $R_{\mathrm{ST}}$ estimates were also

377 highly significant $(p<0.001)$, exhibiting the same pattern as the $F_{\mathrm{ST}}$ estimates and exceeded

378 these for the northern-southern, eight-population, coastal-interior, and subspecies population sets

$379(0.055,0.068,0.053,0.058$, respectively).

$380 \quad$ Both the pairwise $F_{\mathrm{ST}}$ and $R_{\mathrm{ST}}$ estimates from our microsatellite data displayed patterns

381 almost congruent to the pairwise $F_{\mathrm{ST}}$ and $\Phi_{\mathrm{ST}}$ estimates obtained from the mtDNA data. As with

382 the pairwise $F_{\mathrm{ST}}$ and $\Phi_{\mathrm{ST}}$ estimates for the mtDNA data, the pairwise population $F_{\mathrm{ST}}$ values were

383 smaller than and showed patterns similar to the pairwise $R_{\mathrm{ST}}$ estimates, so we chose to present

384 only pairwise $R_{\mathrm{ST}}$ estimates (Tables 2, 3, 4, and $\mathrm{S} 3$ ) here. As with the pairwise $\Phi_{\mathrm{ST}}$ estimates,

385 the pairwise $R_{\mathrm{ST}}$ estimates supported the existence of a distinct Channel Islands population. In

386 further agreement with the mtDNA analyses, the pairwise $F_{\mathrm{ST}}$ and $R_{\mathrm{ST}}$ estimates between Santa

387 Cruz Island and Santa Catalina Island (representing the northern and southern Channel Islands,

388 respectively) were not statistically significant. Pairwise $R_{\mathrm{ST}}$ estimates between the Channel

389 Islands population and the northern, southern, and Haida Gwaii populations were significant at

$3900.130,0.091$, and 0.178 , respectively (Table 3 ). When we grouped samples into eight

391 populations, pairwise $R_{\mathrm{ST}}$ values between the Channel Islands and every other population, except

392 for southern California, were significant, ranging from 0.027 to 0.221 (Table 2). Within the set of

393 eight populations, the highest pairwise $R_{\mathrm{ST}}$ estimate (0.221) was between the Channel Islands

394 and Fairbanks populations. Of the pairwise comparisons amongst the set of eight populations that 
395 included the Channel Islands, the lowest pairwise $R_{\mathrm{ST}}$ estimate $(0.027)$ was between the Channel

396 Islands and southern California populations; the second-lowest estimate (0.094) was between the

397 Channel Islands and Northern Rocky Mountains. Across all loci, we identified three private

398 alleles in the Channel Islands and four in Haida Gwaii, whereas we found only two private

399 alleles in the southern California population (Table S3). When we grouped samples by

400 subspecies, the highest of the pairwise $R_{\mathrm{ST}}$ estimates involving $O$. c. sordida $(0.187)$ was

401 between $O$. c. sordida and O. c. celata. The lowest of these estimates (0.105) was between $O$. c.

402 sordida and O.c. orestera, but the estimate between $O$. c. sordida and O. c. lutescens $(0.106)$

403 was very close (Table 2).

404 When we grouped samples into northern, southern, Channel Islands, and Haida Gwaii

405 populations, we found that the pairwise $R_{\mathrm{ST}}$ estimates between Haida Gwaii and the southern

406 population were significant, but we did not find significance between Haida Gwaii and the

407 northern population nor between the northern and southern populations. When we grouped the

408 samples into eight populations, the pairwise $R_{\mathrm{ST}}$ estimates involving the Haida Gwaii population

409 ranged from 0.002 with the Northern Rocky Mountains to 0.177 with the Channel Islands;

410 estimates were significant with all populations, except for Fairbanks, the Northern Rocky

411 Mountains, and northern California (Table 2). The pairwise $R_{\mathrm{ST}}$ estimates did not suggest much

412 differentiation within the northern populations, as none of the pairwise $R_{\mathrm{ST}}$ estimates involving

413 the Fairbanks, Haida Gwaii, Northern Rocky Mountains, and northern California populations

414 were statistically significant (Table 2). The insignificant pairwise $R_{\mathrm{ST}}$ estimate between the

415 Southern Rocky Mountains and Nevada suggested a connection between these populations;

416 pairwise $R_{\mathrm{ST}}$ estimates between them and all other populations, except for the Northern Rocky

417 Mountains, were significant (Table 2). 
Overall, the microsatellite data revealed little genetic structure and low divergence of

419 populations among our Oreothlypis celata samples. Our PCA analysis did not reveal distinct

420 clustering of the samples by population. Mantel tests utilizing geographic distance (GGD) and

$421 \log (1+\mathrm{GGD})$ versus genetic distance (GD) resulted in weak, statistically significant, positive

422 correlation between geographical distance of $O$. celata sampling localities and genetic distance

423 measured at microsatellite loci $\left(r^{2}=0.015, P=0.006\right.$ for GGD vs. GD and $r^{2}=0.031, P=0.001$ for

$424 \log (1+G G D)$ vs. GD). Our preliminary Structure analyses, in which we did not provide any a

425 priori population information, suggested $K=1$ as the optimal number of genetic clusters. When

426 we grouped the samples into eight pre-designated populations, the mean $\ln \operatorname{Pr}(\mathrm{X} \mid K)$ and $\Delta K$

427 (Evanno, Regnaut \& Goudet, 2005) suggested $K=2$ as the optimal number of genetic clusters

428 (Figure 5). All of the Channel Islands samples had high ancestry $(>83 \%)$ in one of the clusters,

429 whereas the northernmost samples had the highest ancestry in the other cluster. In our analysis of

430 substructure within the seven populations other than the Channel Islands, $\Delta K$ suggested $K=2$ as

431 optimal, but the highest mean $\ln \operatorname{Pr}(\mathrm{X} \mid K)$ was for $K=1$, although the log probability for $K=2$ was

432 very similar. With $K=2$, the southern California, Nevada, and Southern Rocky Mountains

433 populations had high ancestry in one of the clusters and the northern California, Northern Rocky

434 Mountains, Haida Gwaii, and Fairbanks populations had similarly high ancestry in the other

435 genetic cluster (Figure S4). In our analysis of substructure within the Channel Islands samples,

$436 \Delta K$ suggested $K=4$ as optimal, but the highest mean $\ln \operatorname{Pr}(\mathrm{X} \mid K)$ was for $K=1$.

\section{Migration rate estimates}

438 Our IMa2p analyses obtained an upper bound to the effective size of the Channel Islands

439 population, but the analyses did not converge on an upper bound to the effective size of the

440 mainland southern California population. This suggests that the effective size of the mainland 
441 population is likely much higher than that of the Channel Islands. Even though we were unable

442 to accurately calculate migration rates scaled by population size, we were still able to assess the

443 relative population sizes and rates of migration between the two populations. Across all three

444 runs, we calculated a pairwise probability of 1.000 that the current effective population size of

445 the southern California population is greater than that of the Channel Islands population. The

446 probability that the current effective population size of the Channel Islands population is greater

447 than that of the southern California population was $<0.001$. Our migration rate estimates were

448 similar across our three IMa2p runs. Across all three runs, we estimated probabilities of 0.986 to

4491.000 that the rate at which (looking forward in time) the southern California population receives

450 genes from the Channel Islands population is greater than that of the reverse direction. Inversely,

451 we calculated probabilities ranging from 0.000-0.013 that the rate at which (looking forward in

452 time) the Channel Islands receives genes from southern California is greater than migration in

453 the reverse direction.

454 Discussion

455 Genetic analyses of population structure in Oreothlypis celata revealed some structure in 456 portions of the range and high levels of shared alleles across much of the mainland distribution

457 of $O$. celata. The strongest results derived from our present dataset is that both the mitochondrial 458 and microsatellite data suggested that the Channel Islands represent the most genetically distinct 459 population included in our study. We found the highest genetic divergence between the Channel

460 Islands and Fairbanks populations, the two most geographically distant populations in our

461 analyses. More generally, the mitochondrial data suggested higher pairwise divergences among

462 populations than the microsatellite data. The mitochondrial, but not the microsatellite data, 
463 supported statistically significant divergence between northern and southern O. celata. The

464 microsatellite data provided weak support for isolation-by-distance across the species range.

465 Both the mtDNA and microsatellite data suggested that the Channel Islands Oreothlypis

466 celata comprise a separate population that is distinct from the mainland population. Notable is

467 the lack of ND2 haplotype diversity (four haplotypes in 30 individuals with 27 individuals

468 sharing the same haplotype) in the Channel Islands. This is suggestive of a founder event

469 followed by persistence of a relatively small population that has likely fluctuated in size over

470 time, or of strong selection among mitochondrial genotypes to favor one genotype. Our

471 mismatch distribution plots, Tajima's D and Fu's FS results, are consistent with the population

472 recently having expanded in size. The nucleotide diversity within all other populations was much

473 higher than that of the Channel Islands. Within the Channel Islands, the northern and southern

474 island populations (represented by samples from Santa Cruz Island and Santa Catalina Island,

475 respectively) did not display divergence in pairwise $F_{\mathrm{ST}}$ or $\Phi_{\mathrm{ST}}$ comparisons of the mtDNA gene

$476 N D 2$ or in pairwise $F_{\mathrm{ST}}$ or $R_{\mathrm{ST}}$ comparisons of microsatellite data. Sequences from both islands

477 clustered in our phylogenetic trees and haplotype network, suggesting that $O$. c. sordida from the

478 northern and southern Channel Islands constitute one large population. The O. c. sordida

479 individuals from Santa Cruz Island all shared the same ND2 haplotype, which was also present

480 on Santa Catalina Island. We identified three additional ND2 haplotypes unique to Santa Catalina

481 Island. The difference in haplotype diversity could be merely a sampling artifact, but this is

482 unlikely given our sample size of 15 individuals from each island. Although the northern and

483 southern Channel Islands may, in fact, be two separate populations that are diverging, any

484 divergence is likely too recent to be statistically detected with our genetic data, despite the high

485 mutation rates of our markers. 
487 Islands do not undertake a lengthy migration, although individuals may move short distances outside of the breeding season (Gilbert, Sogge \& Van Riper III, 2010). The non-migratory tendency of O.c. sordida, its geographic isolation on the Channel Islands, and the smaller population size on the islands compared to the mainland have all likely contributed to the genetic differentiation that we observed. Interestingly, there also appears to have been cultural evolution of O. c. sordida on the Channel Islands, as evidenced by its slightly slower and more patterned songs compared to more rapid, less patterned songs of the nearest populations of $O$. c. lutescens (Dunn and Garrett, 1997). Based on the distinct phenotypes of island O. c. sordida individuals, Johnson (1972) hypothesized that the Channel Islands O. celata populations have been isolated from the mainland for a substantial period of time. The low degree of divergence and diversity in the mitochondrial data and the paucity of private microsatellite alleles do not support his hypothesis; rather, they suggest that the phenotypic differences in the O. c. sordida populations are of relatively recently derivation. mainland southern California than in the reverse direction, a pattern that also has been detected in horned larks (Eremophila alpestris: Mason et al., 2014). Both mitochondrial and microsatellite data supported O. c. sordida being more closely allied to coastal O. c. lutescens populations than

504 to those of the interior O. c. orestera, contradicting Johnson's (1972) hypothesis of a closer

505 relationship between O. c. orestera and O. c. sordida. However, the Structure analysis in which

506 we excluded the Channel Islands population suggested similar ancestry in the $O$. c. lutescens

507 population of mainland southern California and the O. c. orestera populations of the Southern

508 Rocky Mountains and Nevada (Figure S4). 
Of the four Oreothlypis celata subspecies, our molecular data most strongly supported $O$.

510 c. sordida from the Channel Islands as a distinct group. Although O. c. sordida occurs primarily

511 on the islands, it also breeds locally along the coast of mainland southern California (Unitt, 1984;

512 Dunn \& Garrett, 1997) in close proximity to O. c. lutescens, This distributional pattern is

513 consistent with our finding of greater gene flow from the Channel Islands to mainland southern

514 California than from the mainland to the islands. Recent expansion of the breeding range of $O$..

515 lutescens, especially southward in San Diego County, has closed the distributional gap mapped

516 by Grinnell and Miller (1944) between these two subspecies and caused some to suggest that $O$.

517 c. lutescens is swamping out O. c. sordida on the mainland (Unitt, 2004). Further study

518 combining specimens in known breeding condition with molecular markers is needed to test this

519 hypothesis.

520 Although our microsatellite data showed statistically significant pairwise divergences

521 between all pairs of subspecies except between O. c. lutescens and O. c. celata, our other

522 methods did not recover genetic clusters that clearly distinguished subspecies other than $O . c$.

523 sordida. Ongoing gene flow between $O$. celata subspecies may be acting to prevent greater

524 divergence of populations. Using microsatellite data, Bull et al. (2010) calculated significant

525 gene flow from populations of O. c. lutescens into O. c. celata. Gilbert and West (2015) provided

526 further evidence of gene flow between these two subspecies by identifying $O$. celata individuals

527 from Alaska that were morphologically intermediate between O. c. celata and O. c. lutescens. 528

529 Conclusions

530 Overall, our results suggest that the differentiation seen in phenotypic and ecologic

531 characters across $O$. celata is recent. Similar to the findings of Bull et al. (2010) for northern 
532 populations of $O$. c. celata and $O$. c. lutescens, genetic distances and clusters we observed across

533 the western North American range of $O$. celata are consistent with high levels of gene flow

534 combined with weak isolation-by-distance. Moreover, our finding that the strongest signal of

535 population divergence occurs on the Channel Islands is consistent with geographic isolation,

536 reduced migration tendency, and relatively low levels of gene flow from the mainland to the

537 islands. The observation that cultural evolution in songs of $O$. celata has occurred on the

538 Channel Islands (Dunn and Garrett, 1997) also supports the distinctiveness of this taxon on the

539 islands. Future research that includes vocal as well as genomic data will further advance our

540 understanding of the origin and evolution of birds on the Channel Islands. In summary, island

541 isolation, subspecies (delineation by morphology, ecological and life-history characteristics), and

542 isolation-by-distance, in that order, are the likely best explanatory variables of the geographic

543 structure we detected across the range of $O$. celata.

545 Acknowledgements

546 We thank Anand Varma for permission to reproduce the photos included as Figures S1

547 and S2. For access to specimens and genetic samples, we thank Andrew Johnson, Alison Boyer,

548 and the Museum of Southwestern Biology; Kevin Burns and the San Diego State University

549 Museum of Biodiversity; Vicki Friesen, Kimberley Lemmen, Scott Taylor, Theresa Burg, and

550 Roger Bull of Queen's University and the Canadian Museum of Nature; Jocelyn Hudon and the

551 Royal Alberta Museum; and the Museum of Vertebrate Zoology. For assistance in the field, we

552 thank Jessica Castillo and Janette Havens. We appreciate support provided by Mark R.

553 Stromberg in our collection activities at Hastings Natural History Reservation. We thank Monica

554 J. Albe for help with specimen preparations and field equipment, Lydia Smith for laboratory 
555 support, Michelle Koo for assistance with graphics construction, and Anna Sellas for advice

556 regarding laboratory work and data analyses. Kimball Garrett and two anonymous reviewers

557 provided helpful comments that improved an earlier version of this manuscript. 


\section{References}

559 Bermingham E, Rohwer S, Freeman S, Wood C. 1992. Vicariance Biogeography in the

560 Pleistocene and Speciation in North American Wood Warblers: A Test of Mengel's

561 Model. Proceedings of the National Academy of Sciences 89:6624-6628.

562 Bowie RCK, Feldheim KA, Hanna ZR, Sellas AB, Cicero C. 2017. Development of

563 Polymorphic Tetranucleotide Microsatellite Markers for New World Warblers (Aves:

564 Passeriformes: Parulidae) with Broad Cross-species Utility. The Wilson Journal of

565 Ornithology 129:401-407. DOI: 10.1676/16-110.1.

566 Brunsfeld SJ, Sullivan J, Soltis DE, Soltis PS. 2001. Comparative phylogeography of

567 northwestern North America: a synthesis. In: Integrating Ecology and Evolution in a

568 Spatial Context. Oxford: Blackwell Science, 319-340.

Bull RD, McCracken A, Gaston AJ, Birt TP, Friesen VL. 2010. Evidence of Recent Population Differentiation in Orange-crowned Warblers (Vermivora celata) in Haida Gwaii. The Auk 127:23-34. DOI: 10.1525/auk.2009.09159.

Burg TM, Gaston AJ, Winker K, Friesen VL. 2006. Effects of Pleistocene glaciations on population structure of North American chestnut-backed chickadees. Molecular Ecology 15:2409-2419. DOI: 10.1111/j.1365-294X.2006.02957.x.

575 Caballero IC, Ashley MV. 2011. Genetic analysis of the endemic island loggerhead shrike, Lanius ludovicianus anthonyi. Conservation Genetics 12:1485-1493. DOI: 10.1007/s10592-011-0247-4.

578 Chhatre VE. 2016. Distruct. Version 2.2. [Accessed 2018 Jun 21]. Available from: http://www.crypticlineage.net/pages/distruct.html. 
580 Chhatre VE, Emerson KJ. 2017. StrAuto: automation and parallelization of STRUCTURE

581 analysis. BMC Bioinformatics 18:192. DOI: 10.1186/s12859-017-1593-0.

582 Chhatre VE, Emerson KJ. 2018. StrAuto. Version 1.0. [Accessed 2018 Jun 21]. Available from:

583 http://www.crypticlineage.net/pages/software.html.

584 Clement M, Posada D, Crandall KA. 2000. TCS: a computer program to estimate gene

585 genealogies. Molecular ecology 9:1657-1659.

586 Crawford DJ. 2012. Oceanic islands as evolutionary laboratories. Access Science. DOI:

587 10.1036/1097-8542.YB120241.

588 Delaney KS, Zafar S, Wayne RK. 2008. Genetic Divergence and Differentiation within the Western Scrub-Jay (Aphelocoma californica). The Auk 125:839-849. DOI: 10.1525/auk.2008.07088.

591 Diamond JM. 1969. Avifaunal Equilibria and Species Turnover Rates on the Channel Islands of California. Proceedings of the National Academy of Sciences 64:57-63.

Dunn JL, Garrett KL. 1997. A Field Guide to Warblers of North America. New York, New York: Houghton Mifflin Company.

Dupanloup I, Schneider S, Excoffier L. 2002. A simulated annealing approach to define the genetic structure of populations. Molecular Ecology 11:2571-2581. DOI: 10.1046/j.1365-294X.2002.01650.x.

Earl D. 2014. Structure Harvester. Version 0.6.94. [Accessed 2018 Jun 21]. Available from: https://github.com/dentearl/structureHarvester.

600 Earl DA, vonHoldt BM. 2012. STRUCTURE HARVESTER: a website and program for 601 visualizing STRUCTURE output and implementing the Evanno method. Conservation Genetics Resources 4:359-361. DOI: 10.1007/s12686-011-9548-7. 
603 Evanno G, Regnaut S, Goudet J. 2005. Detecting the number of clusters of individuals using the 604 software structure: a simulation study. Molecular Ecology 14:2611-2620. DOI:

605 10.1111/j.1365-294X.2005.02553.x.

606 Excoffier L, Laval G, Schneider S. 2007. Arlequin (version 3.0): An integrated software package 607 for population genetics data analysis. Evolutionary Bioinformatics Online 1:47-50.

608

609

610

611

612

613

614

615

616

617

618

619

620

621

622

623

Excoffier L, Smouse PE, Quattro JM. 1992. Analysis of molecular variance inferred from metric distances among DNA haplotypes: application to human mitochondrial DNA restriction data. Genetics 131:479-491.

Falush D, Stephens M, Pritchard JK. 2003. Inference of Population Structure Using Multilocus Genotype Data: Linked Loci and Correlated Allele Frequencies. Genetics 164:15671587.

Foster MS. 1967. Molt Cycles of the Orange-crowned Warbler. The Condor 69:169-200. DOI: 10.2307/1366606.

Fu Y-X. 1997. Statistical Tests of Neutrality of Mutations Against Population Growth, Hitchhiking and Background Selection. Genetics 147:915-925.

Gilbert WM, Sogge MK, Van Riper III C. 2010. Orange-crowned Warbler (Oreothlypis celata), version 2.0. In: The Birds of North America (P. G. Rodewald, editor). Ithaca, New York, U.S.A.: Cornell Lab of Ornithology,.

Gilbert WM, West GC. 2015. Morphological expression in putative intergrades between two subspecies of Orange-crowned Warbler (Oreothlypis celata) on the Kenai Peninsula, Alaska. The Wilson Journal of Ornithology 127:29-42. DOI: 10.1676/13-153.1. 
624 Ginot F, Bordelais I, Nguyen S, Gyapay G. 1996. Correction of Some Genotyping Errors in 625 Automated Fluorescent Microsatellite Analysis by Enzymatic Removal of One Base 626 Overhangs. Nucleic Acids Research 24:540-541. DOI: 10.1093/nar/24.3.540.

627 Goodman SJ. 1997. RST Calc: a collection of computer programs for calculating estimates of 628 genetic differentiation from microsatellite data and determining their significance. Molecular Ecology 6:881-885. DOI: 10.1111/j.1365-294X.1997.tb00143.x.

630 Goudet J. 1995. FSTAT (Version 1.2): A Computer Program to Calculate F-Statistics. Journal of 631 Heredity 86:485-486. DOI: 10.1093/oxfordjournals.jhered.a111627.

632 Goudet J. 2001. FSTAT. Version 2.9.3.2. A program to estimate and test gene diversities and 633 fixation indices. [Accessed 2017 Nov 21]. Available from: http://www2.unil.ch/popgen/softwares/fstat.htm. Lausanne University, Lausanne, Switzerland.

636 Greenberg R, Danner RM. 2013. Climate, ecological release and bill dimorphism in an island 637 songbird. Biology Letters 9. DOI: 10.1098/rsbl.2013.0118.

638 Grinnell J, Miller AH. 1944. The distribution of the birds of California. Cooper Ornithological 639 Cub. Berkeley, California, 608 pp.

640 Gunderson AR, Mahler DL, Leal M. 2018. Thermal niche evolution across replicated Anolis 641 lizard adaptive radiations. Proc. R. Soc. B 285:20172241. DOI: 10.1098/rspb.2017.2241.

642 Hanna ZR, Cicero C, Bowie RCK. 2018. ocwa-popgen. Zenodo. DOI: 10.5281/zenodo.1648690. 643 Harpending HC, Batzer MA, Gurven M, Jorde LB, Rogers AR, Sherry ST. 1998. Genetic traces 644 of ancient demography. Proceedings of the National Academy of Sciences 95:1961-1967. 645 Harpending HC, Sherry ST, Rogers AR, Stoneking M. 1993. The Genetic Structure of Ancient Human Populations. Current Anthropology 34:483-496. DOI: 10.2307/2743761. 
647 Hubisz MJ, Falush D, Stephens M, Pritchard JK. 2009. Inferring weak population structure with 648 the assistance of sample group information. Molecular Ecology Resources 9:1322-1332. 649 DOI: $10.1111 /$ j.1755-0998.2009.02591.x.

650 Jakobsson M, Rosenberg NA. 2007. CLUMPP: a cluster matching and permutation program for 651 dealing with label switching and multimodality in analysis of population structure.

652 Bioinformatics 23:1801-1806. DOI: 10.1093/bioinformatics/btm233.

653 Johnson NK. 1972. Origin and Differentiation of the Avifauna of the Channel Islands, 654 California. The Condor 74:295-315. DOI: $10.2307 / 1366591$.

655 Jones HL, Diamond JM. 1976. Short-Time-Base Studies of Turnover in Breeding Bird 656 Populations on the California Channel Islands. The Condor 78:526-549. DOI: $10.2307 / 1367103$.

Karin BR, Cicero C, Koo MS, Bowie RCK. 2018. The role of history and ecology as drivers of 659 song divergence in Bell's and Sagebrush sparrows (Artemisiospiza, Aves: Passerellidae). Biological Journal of the Linnean Society 125:421-440. DOI: 10.1093/biolinnean/bly090. Ecology 11:2445-2449. DOI: 10.1046/j.1365-294X.2002.01612.x.

Liebers D, Helbig AJ, De Knijff P. 2001. Genetic differentiation and phylogeography of gulls in 665 the Larus cachinnans-fuscus group (Aves: Charadriiformes). Molecular Ecology

666 10:2447-2462. DOI: 10.1046/j.0962-1083.2001.01370.x.

667 Lomolino MV. 2005. Body size evolution in insular vertebrates: generality of the island rule. 668 Journal of Biogeography 32:1683-1699. DOI: 10.1111/j.1365-2699.2005.01314.x. 
669 Losos JB, Ricklefs RE. 2009. Adaptation and diversification on islands. Nature 457:830-836.

$670 \quad$ DOI: $10.1038 /$ nature07893.

671 Lovette IJ, Bermingham E, Sheldon F. 2002. What is a wood-warbler? molecular

672 characterization of a monophyletic parulidae. The Auk 119:695-714. DOI: 10.1642/0004-

673 8038(2002)119[0695:WIAWWM]2.0.CO;2.

674 Lynch JF, Johnson NK. 1974. Turnover and Equilibria in Insular Avifaunas, with Special

675 Reference to the California Channel Islands. The Condor 76:370-384. DOI:

676 $10.2307 / 1365812$

677

678

679

680

681

682

683

684

685

686

687

688

689

690

691

Marjoram P, Donnelly P. 1994. Pairwise comparisons of mitochondrial DNA sequences in subdivided populations and implications for early human evolution. Genetics 136:673683.

Mason NA, Title PO, Cicero C, Burns KJ, Bowie RCK. 2014. Genetic variation among western populations of the Horned Lark (Eremophila alpestris) indicates recent colonization of the Channel Islands off southern California, mainland-bound dispersal, and postglacial range shifts. The Auk 131:162-174. DOI: 10.1642/AUK-13-181.1.

Mundy NI, Winchell CS, Woodruff DS. 1997. Genetic differences between the endangered San Clemente Island loggerhead shrike Lanius ludovicianus mearnsi and two neighbouring subspecies demonstrated by mtDNA control region and cytochrome $b$ sequence variation. Molecular Ecology 6:29-37. DOI: 10.1046/j.1365-294X.1997.00149.x.

Nei M. 1972. Genetic Distance between Populations. The American Naturalist 106:283-292. DOI: $10.2307 / 2459777$.

Nei M. 1987. Molecular Evolutionary Genetics. New York, New York: Columbia University Press. 
692 Oberholser HC. 1905. The Forms of Vermivora celata (Say). The Auk 22:242-247. DOI:

$693 \quad 10.2307 / 4070156$.

694 Peakall R, Smouse PE. 2006. genalex 6: genetic analysis in Excel. Population genetic software 695 for teaching and research. Molecular Ecology Notes 6:288-295. DOI: 10.1111/j.1471$696 \quad$ 8286.2005.01155.x.

697 Peakall R, Smouse PE. 2012. GenAlEx 6.5: genetic analysis in Excel. Population genetic 698 software for teaching and research—an update. Bioinformatics 28:2537-2539. DOI:

699 10.1093/bioinformatics/bts460.

700 Posada D, Crandall KA. 2001. Intraspecific gene genealogies: trees grafting into networks. Trends in Ecology \& Evolution 16:37-45. DOI: 10.1016/S0169-5347(00)02026-7.

702 703

704 705

706

Pritchard JK, Falush D, Hubisz MJ. 2012. Structure. Version 2.3.4. [Accessed 2018 Jun 21]. Available from: https:/web.stanford.edu/group/pritchardlab/structure.html.

Pritchard JK, Stephens M, Donnelly P. 2000. Inference of Population Structure Using Multilocus Genotype Data. Genetics 155:945-959.

Raj A, Stephens M, Pritchard JK. 2014. fastSTRUCTURE: Variational Inference of Population Structure in Large SNP Data Sets. Genetics 197:573-589. DOI: 10.1534/genetics.114.164350.

Raymond M, Rousset F. 1995. GENEPOP (Version 1.2): Population Genetics Software for Exact Tests and Ecumenicism. Journal of Heredity 86:248-249.

Rice WR. 1989. Analyzing Tables of Statistical Tests. Evolution 43:223. DOI: 10.2307/2409177. Ridgway R. 1872. Helminthophaga celata var. lutescens. In: The American Journal of Science and Arts. Third Series. Volume 4. New Haven: Tuttle, Morehouse \& Taylor, 457. 
714 Rogers AR, Harpending H. 1992. Population growth makes waves in the distribution of pairwise 715 genetic differences. Molecular Biology and Evolution 9:552-569.

716 Rousset F. 2008. GENEPOP'007: a complete re-implementation of the GENEPOP software for 717 Windows and Linux. Molecular Ecology Resources 8:103-106. DOI: 10.1111/j.1471-

Say T. 1823. Sylvia celatus. In: Account of an expedition from Pittsburgh to the Rocky Mountains, performed in the years 1819 and '20, by order of the Hon. J.C. Calhoun, Sec'y of War: under the command of Major Stephen H. Long. From the notes of Major

Schoenherr AA, Feldmeth CR, Emerson MJ. 1999. Natural history of the islands of California. Long, Mr. T. Say, and other gentlemen of the exploring party. Compiled by Edwin James,

Sethuraman A. 2017. IMa2p. Version 58a02604e58b6a2bc3c1ccbb75767dafbb6fa781. [Accessed 2018 Jun 21]. Available from: https://github.com/arunsethuraman/ima2p.

Sethuraman A, Hey J. 2015. IMa2p - parallel MCMC and inference of ancient demography under the Isolation with migration (IM) model. Molecular Ecology Resources 16:206-

Slatkin M, Hudson RR. 1991. Pairwise comparisons of mitochondrial DNA sequences in stable and exponentially growing populations. Genetics 129:555-562.

Soltis DE, Gitzendanner MA, Strenge DD, Soltis PS. 1997. Chloroplast DNA intraspecific phylogeography of plants from the Pacific Northwest of North America. Plant Systematics and Evolution 206:353-373. DOI: 10.1007/BF00987957. 
737 Sorenson MD, Ast JC, Dimcheff DE, Yuri T, Mindell DP. 1999. Primers for a PCR-Based

738 Approach to Mitochondrial Genome Sequencing in Birds and Other Vertebrates.

739 Molecular Phylogenetics and Evolution 12:105-114. DOI: 10.1006/mpev.1998.0602.

740 Stamatakis A, Hoover P, Rougemont J. 2008. A Rapid Bootstrap Algorithm for the RAxML

741 Web Servers. Systematic Biology 57:758-771. DOI: 10.1080/10635150802429642.

742 Swenson NG, Howard DJ. 2005. Clustering of Contact Zones, Hybrid Zones, and 743 Phylogeographic Breaks in North America. The American Naturalist 166:581-591. DOI:

744 10.1086/491688.

745

746

747

748

749

750

751

752

753

754 755

Swofford DL. 2003. PAUP*. Phylogenetic Analysis Using Parsimony (*and Other Methods). Version 4. Sinauer Associates, Sunderland, Massachusetts.

Tajima F. 1989. Statistical method for testing the neutral mutation hypothesis by DNA polymorphism. Genetics 123:585-595.

Tange O. 2011. GNU Parallel: The Command-Line Power Tool. ;login: The USENIX Magazine $36: 42-47$.

Townsend CH. 1890. Helminthophila celata sordida. In: Proceedings of the United States National Museum. Volume 13. Washington, D.C.: Government Printing Office, 139.

Unit P. 2004. San Diego County Bird Atlas. Sunbelt Publications, $1^{\text {st }}$ Edition, 766 pg.

Unit P. 1984. The birds of San Diego County. San Diego Society of Natural History Memoir 13, Luster Industries, San Diego, 276.

Van Oosterhout C, Hutchinson WF, Wills DPM, Shipley P. 2004. MICRO-CHECKER: software for identifying and correcting genotyping errors in microsatellite data. Molecular Ecology Notes 4:535-538. DOI: 10.1111/j.1471-8286.2004.00684.x. 
759 Wilson A, Arcese P, Keller LF, Pruett CL, Winker K, Patten MA, Chan Y. 2009. The

760 contribution of island populations to in situ genetic conservation. Conservation Genetics

761 10:419. DOI: 10.1007/s10592-008-9612-3.

762 


\section{Figure 1}

Figure 1. Sample map and microsatellite allele pie charts.

Depicted here are all Oreothlypis celata sampling localities and the associated population designations used in this study. Population numbers correspond to the "Pop \#" column in Table 1. We also provide an across-population comparison of the percent prevalence of a subset of the alleles found in our samples for the three most variable (Vce102, Vce128, and Vce167) and three least variable (Vce34, Vce70, and Vce179) loci. For each population, we present the percent prevalence of both the three most common and the rare alleles. We define rare alleles as those whose average occurrence in populations represents less than $5 \%$ of the allele pool. Loci Vce70 and Vce102 were exceptions to this definition. Due to the small total number, we included all five detected alleles for Vce70. There were so many rare alleles for Vce102 that we defined the rare alleles for this locus as those with an average population occurrence of $<1 \%$ of the total allele pool. For the least variable loci, we depict the percent prevalence of the three most common alleles and the rare alleles together in the same pie chart. Due to the large number of rare alleles in the most variable loci, we have depicted the rare alleles in a separate pie chart. For Vce102, Vce128, and Vce167, the left pie charts display the percent prevalence of the three most common alleles and the right graphs represent the percent prevalence of the rare alleles. The prevalence percentages depicted in the pie charts are all relative as the total prevalence of all alleles must sum to one. We recommend that the reader compare graphs vertically, across populations. A given color represents different alleles across columns. 


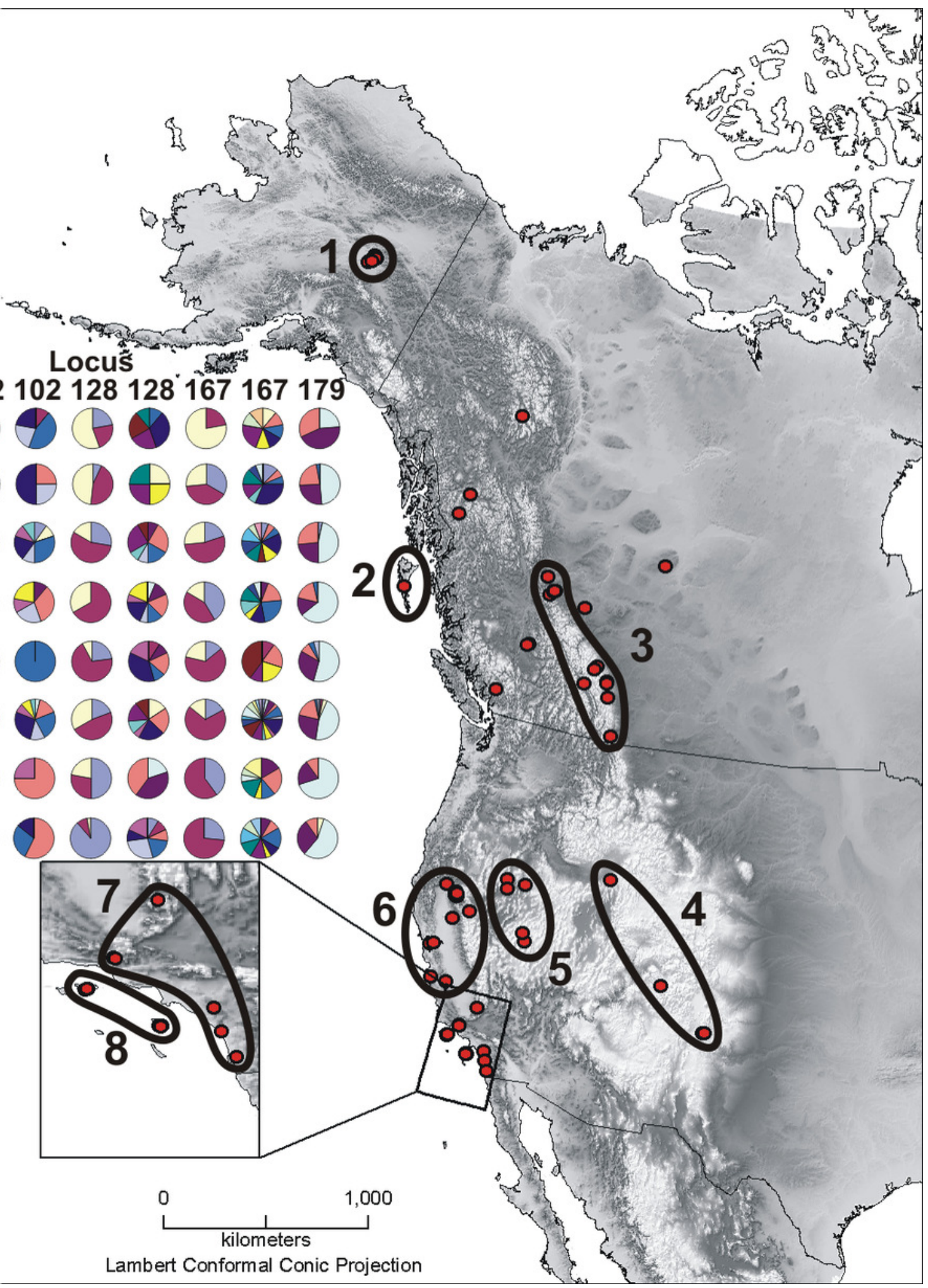




\section{Figure 2}

Figure 2. ND2 haplotype network.

(A) depicts the ND2 haplotype network shaded according to samples' designation in the northern or southern population. (B) is the haplotype network shaded using sample assignment under the eight population grouping arrangement, a more fine-scale partitioning than the north-south grouping schema. The haplotype numbers in (A) correspond with the numbers in Table S1. Circle sizes are proportional to the number of individuals with each haplotype. Lines connect haplotypes that differ by one mutation. Dots represent inferred haplotypes. Hash marks indicate the number of mutations between haplotypes separated by more than one mutational difference. For one circle of each size, we have labeled the number of individuals represented by that circle following " $n=$ ". 


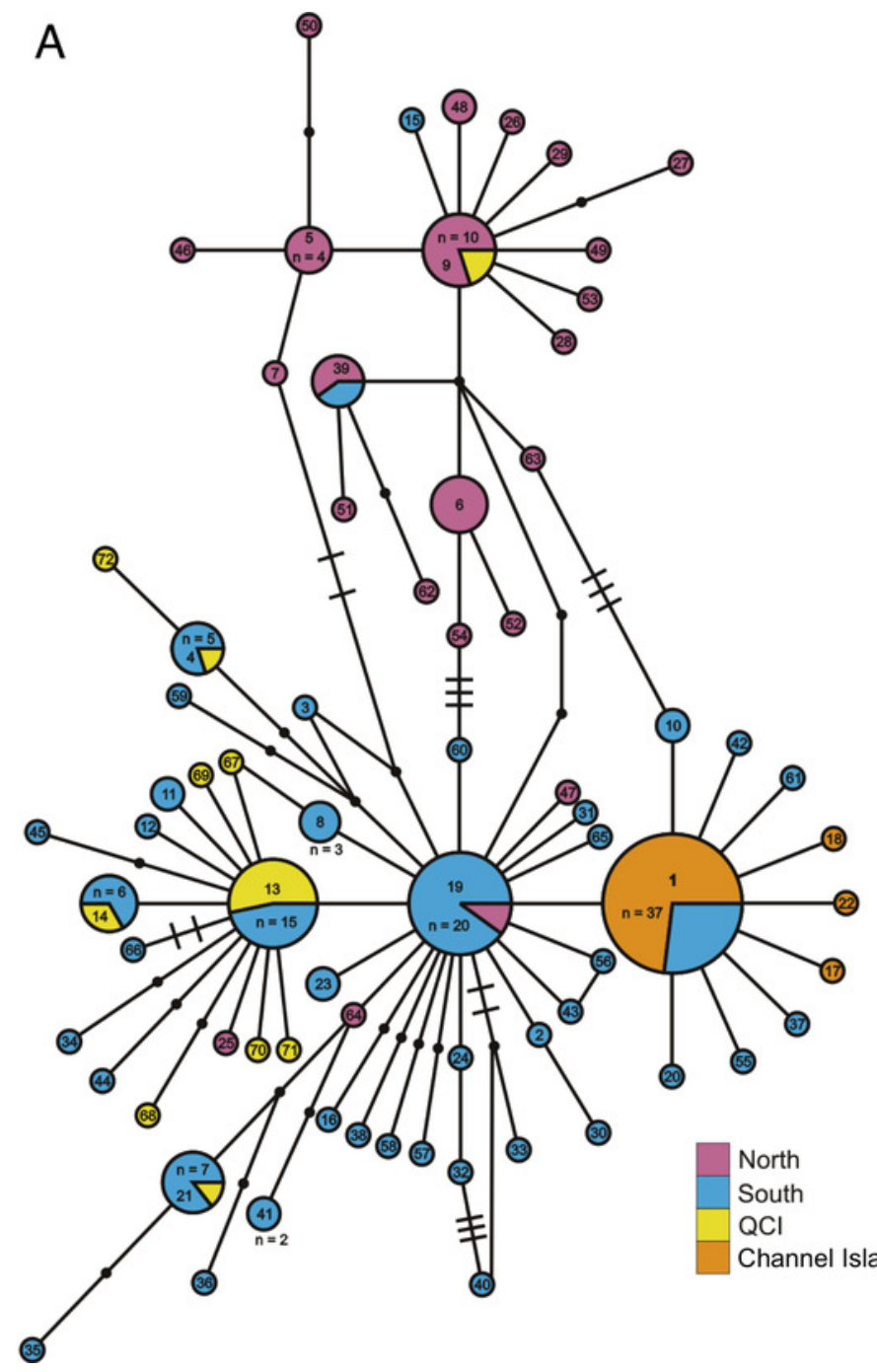

B

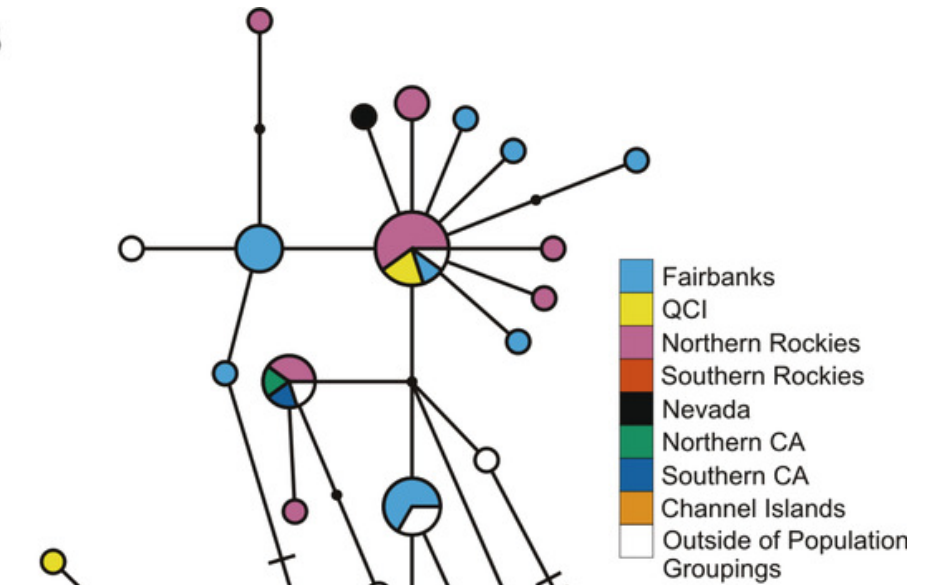

\section{西}
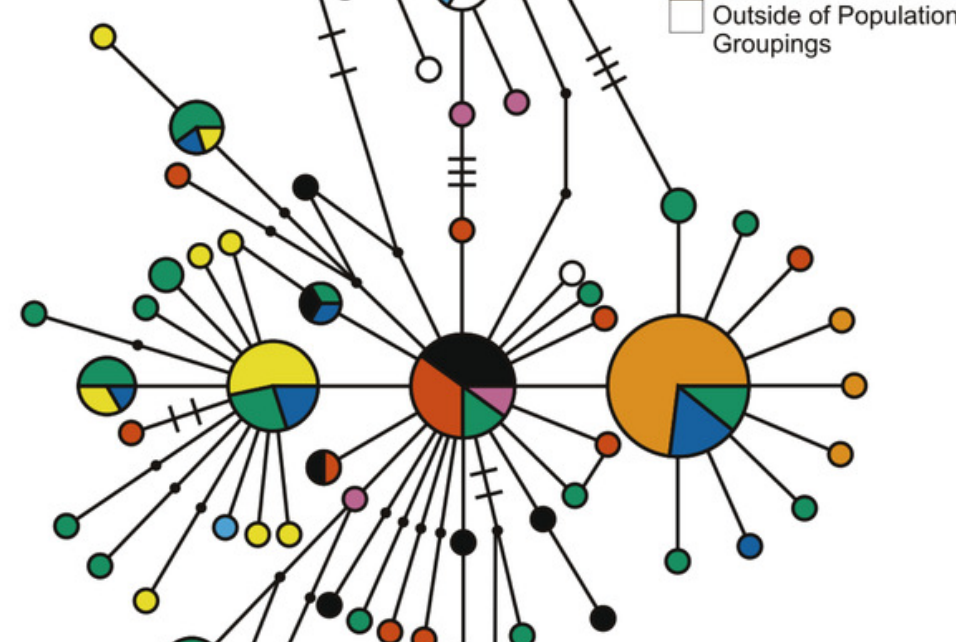


\section{Figure 3}

Figure 3. ND2 haplotype network with subspecies population grouping.

This is the ND2 haplotype network colored by the subspecies designations of samples. The haplotype numbers correspond with the numbers in Table S1. The size of each circle is proportional to the number of individuals with that haplotype. Lines connect haplotypes that differ by one mutation. Dots represent inferred haplotypes. Hash marks indicate the number of mutations between haplotypes separated by more than one mutation. 


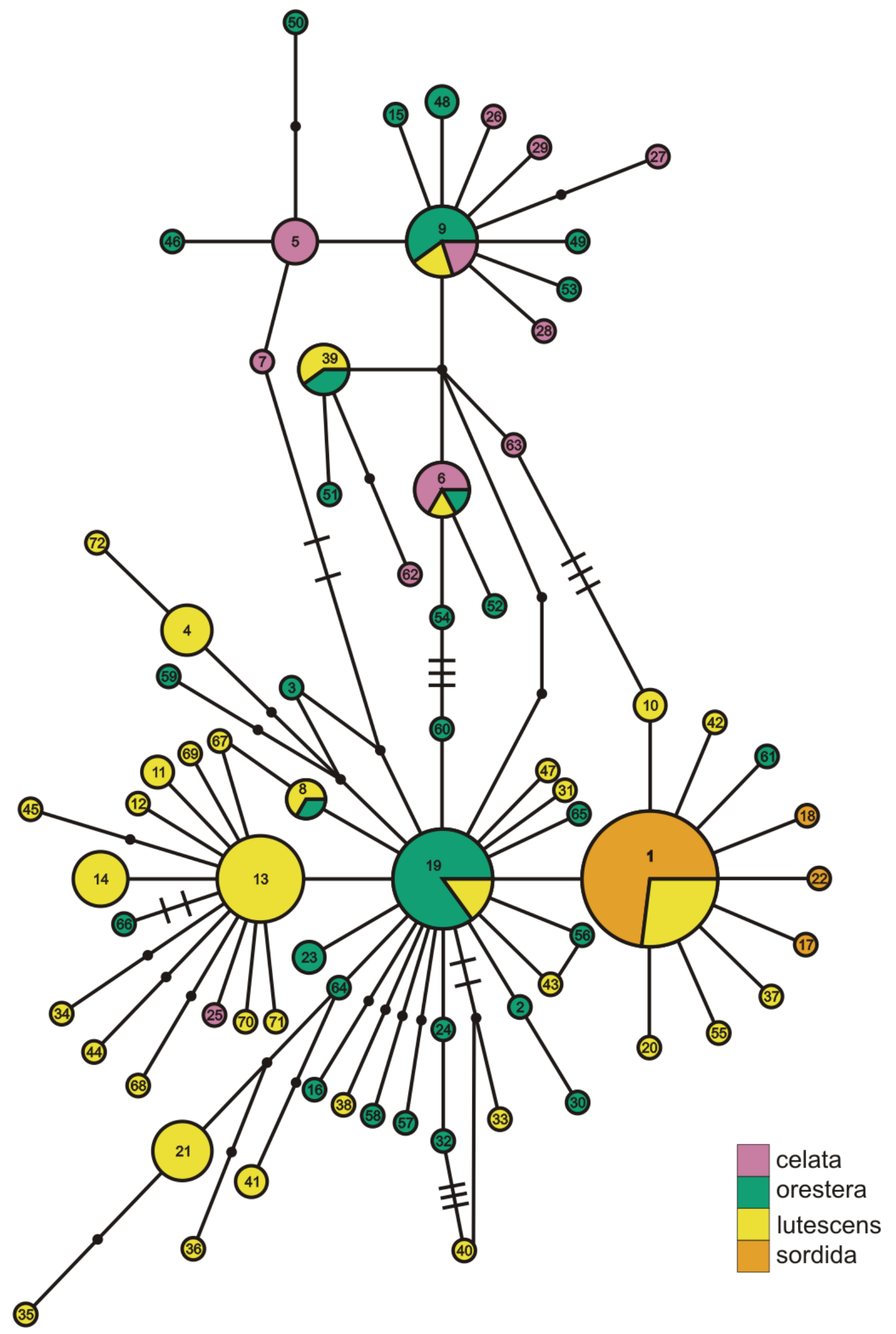

Peer) reviewing PDF | (2018:09:31580:2:0:NEW 27 Jun 2019) 


\section{Figure 4}

Figure 4. Mismatch distributions.

(A-J) are mismatch distributions for ten populations. Square points connected by smooth lines represent observed distributions. Circular points connected by dotted lines represent expected distributions for a growing population with the same mean. 

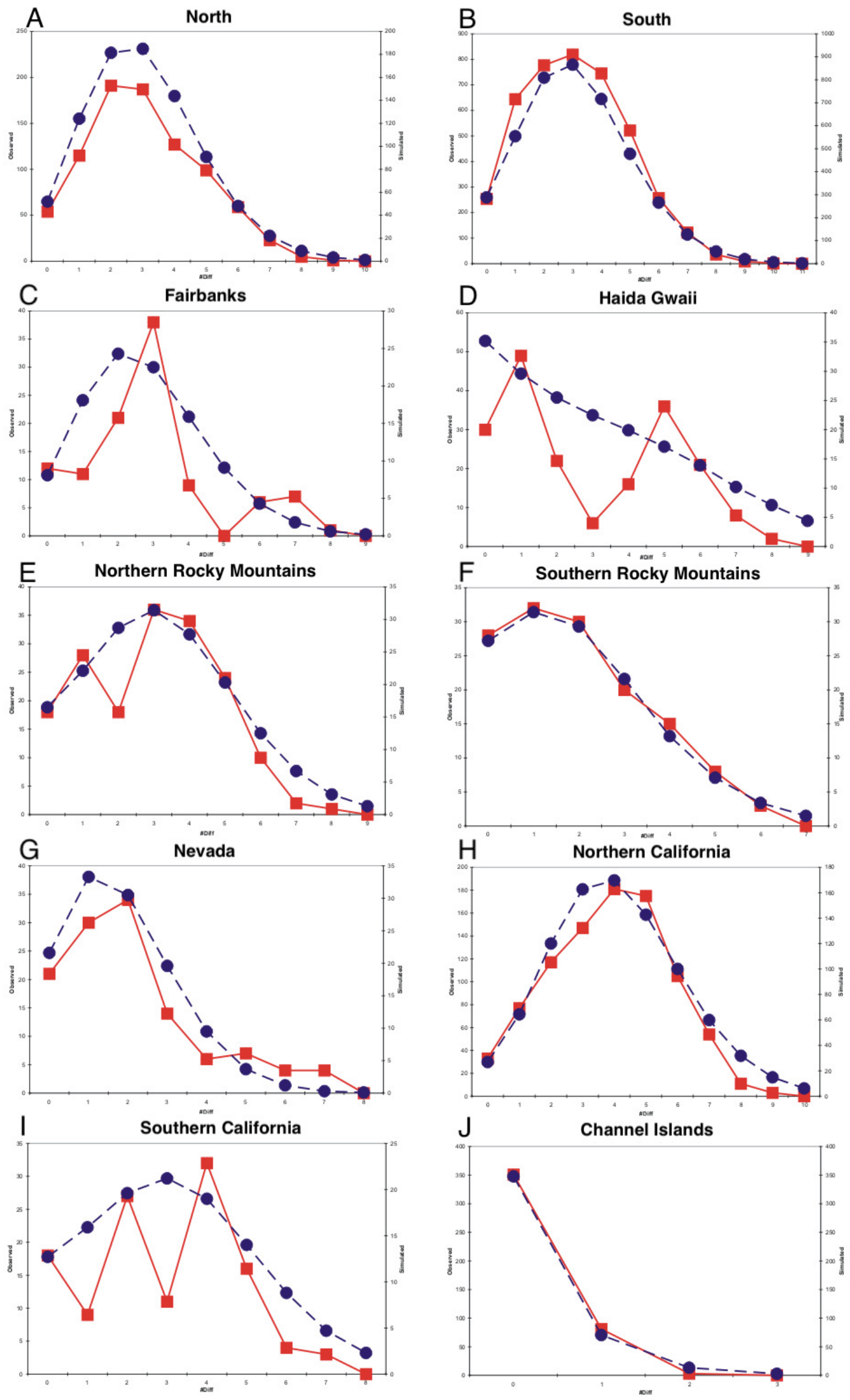

Peer) reviewing PDF | (2018:09:31580:2:0:NEW 27 Jun 2019) 


\section{Figure 5}

Figure 5. Structure plot for $K=2$ with Channel Islands population included.

Different colors represent the two genetic clusters identified by Structure. Each vertical bar represents an individual Oreothlypis celata. The height of each color in a given bar illustrates the proportion of ancestry derived from each genetic cluster for that individual. When sample locality was excluded as a prior, $\mathrm{K}=1$ was recovered.

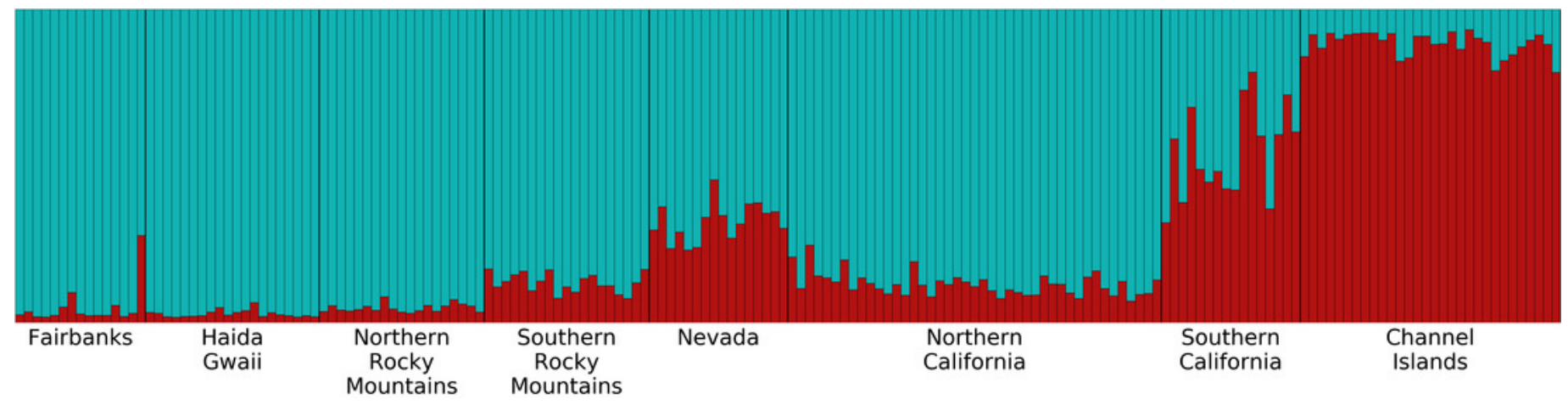




\section{Table $\mathbf{1}$ (on next page)}

Table 1. Microchondrial sequence data summary statistics.

This table presents summary statistics for the ND2 mitochondrial sequence data for each population. We list the number of individuals sampled $(N)$ and the number of haplotypes in each population. We provide estimates of haplotype diversity $(h)$ with standard deviation, nucleotide diversity $(\pi)$ with standard deviation, Tajima's D, Fu's Fs, and Harpending's Raggedness Index. The named "North" population includes Pop 1 and 3. The "South" population includes Pop 4 through 7. Values followed by one asterisk are significant with $p<$ 0.05 and values followed by two asterisks are significant with $p<0.001$. 


\begin{tabular}{|c|c|c|c|c|c|c|c|c|}
\hline $\begin{array}{c}\text { Pop } \\
\#\end{array}$ & Population & $N$ & $\begin{array}{l}\text { Number of } \\
\text { haplotypes }\end{array}$ & $h$ & $\pi$ & $\begin{array}{c}\text { Tajima's } \\
\text { D }\end{array}$ & Fu's Fs & $\begin{array}{l}\text { Harpending's s } \\
\text { Raggedness } \\
\text { Index }\end{array}$ \\
\hline & North & 42 & 23 & $0.94+/-0.02$ & $0.0029+/-0.0017$ & $-1.80^{*}$ & $-16.50 * *$ & 0.023 \\
\hline & South & 92 & 42 & $0.94+/-0.01$ & $0.0030+/-0.0017$ & $-2.35^{* *}$ & $-26.42 * *$ & 0.018 \\
\hline 1 & Fairbanks & 15 & 9 & $0.89+/-0.06$ & $0.0027+/-0.0017$ & -1.16 & $-3.05^{*}$ & 0.126 \\
\hline 2 & Haida Gwaii & 20 & 11 & $0.84+/-0.08$ & $0.0028+/-0.0017$ & $-1.73 *$ & $-4.04 *$ & 0.063 \\
\hline 3 & Northern Rocky Mtns. & 19 & 11 & $0.89+/-0.06$ & $0.0029+/-0.0018$ & -1.31 & $-4.19 *$ & 0.030 \\
\hline 4 & Southern Rocky Mtns. & 17 & 10 & $0.79+/-0.10$ & $0.0019+/-0.0013$ & $-2.25 * *$ & $-5.44 * *$ & 0.012 \\
\hline 5 & Nevada & 16 & 10 & $0.83+/-0.10$ & $0.0020+/-0.0013$ & $-2.10^{*}$ & $-5.51 * *$ & 0.041 \\
\hline 6 & Northern California & 43 & 25 & $0.96+/-0.01$ & $0.0037+/-0.0021$ & $-2.07 *$ & $-16.47 * *$ & 0.018 \\
\hline 7 & Southern California & 16 & 9 & $0.85+/-0.08$ & $0.0028+/-0.0017$ & $-1.71 *$ & -2.66 & 0.105 \\
\hline 8 & Channel Islands & 30 & 4 & $0.19+/-0.10$ & $0.0002+/-0.0003$ & $-1.73 *$ & $-3.38 * *$ & 0.417 \\
\hline
\end{tabular}

2

3

4 


\section{Table 2 (on next page)}

Table 2. Population pairwise divergence statistics.

This table presents divergence statistics for pairwise population comparisons calculated using the ND2 mitochondrial DNA sequence ( $\Phi_{\mathrm{ST}}$ above diagonal) and microsatellite data $\left(R_{\mathrm{ST}}\right.$ below diagonal). Values followed by asterisks are significant after applying a Bonferroni correction $(p<0.002)$. See Table S1 for the samples included in each population. 


\begin{tabular}{lcccccccc}
\hline & Fairbanks & $\begin{array}{c}\text { Haida } \\
\text { Gwaii }\end{array}$ & $\begin{array}{c}\text { Northern } \\
\text { Rocky } \\
\text { Mountains }\end{array}$ & $\begin{array}{c}\text { Southern } \\
\text { Rocky } \\
\text { Mountains }\end{array}$ & Nevada & $\begin{array}{c}\text { Northern } \\
\text { California }\end{array}$ & $\begin{array}{c}\text { Southern } \\
\text { California }\end{array}$ & $\begin{array}{c}\text { Channel } \\
\text { Islands }\end{array}$ \\
\hline Fairbanks & - & $0.525^{*}$ & 0.011 & $0.584^{*}$ & $0.532^{*}$ & $0.486^{*}$ & $0.528^{*}$ & $0.809^{*}$ \\
\hline Haida Gwaii & 0.029 & - & $0.481^{*}$ & $0.152^{*}$ & $0.166^{*}$ & 0.061 & 0.110 & $0.564^{*}$ \\
\hline $\begin{array}{l}\text { Northern } \\
\text { Rocky } \\
\text { Mountains }\end{array}$ & 0.005 & 0.002 & - & $0.521^{*}$ & $0.467^{*}$ & $0.440^{*}$ & $0.472^{*}$ & $0.754^{*}$ \\
\hline $\begin{array}{l}\text { Southern } \\
\text { Rocky } \\
\text { Mountains }\end{array}$ & $0.119^{*}$ & $0.087^{*}$ & 0.026 & - & 0.006 & 0.016 & 0.047 & $0.531^{*}$ \\
\hline Nevada & $0.141^{*}$ & $0.092^{*}$ & 0.033 & 0.000 & - & 0.035 & 0.069 & $0.558^{*}$ \\
\hline $\begin{array}{l}\text { Northern } \\
\text { California }\end{array}$ & 0.027 & 0.020 & 0.000 & $0.038^{*}$ & $0.054^{*}$ & - & 0.000 & $0.245^{*}$ \\
\hline $\begin{array}{l}\text { Southern } \\
\text { California }\end{array}$ & $0.103^{*}$ & $0.079^{*}$ & 0.025 & $0.089^{*}$ & $0.095^{*}$ & 0.040 & - & $0.261^{*}$ \\
\hline $\begin{array}{l}\text { Channel } \\
\text { Islands }\end{array}$ & $0.221^{*}$ & $0.177^{*}$ & $0.094^{*}$ & $0.145^{*}$ & $0.123^{*}$ & $0.111^{*}$ & 0.027 & - \\
\hline
\end{tabular}

1 


\section{Table 3 (on next page)}

Table 3. Pairwise divergence statistics of the north, south, and island populations.

We here present the results of pairwise population comparisons with ND2 mitochondrial DNA sequence ( $\Phi_{\mathrm{ST}}$ above diagonal) and microsatellite $\left(R_{\mathrm{ST}}\right.$ below diagonal) data. Values followed by asterisks are significant after applying a Bonferroni correction $(p<0.008)$. 


\begin{tabular}{lcccc}
\hline & North & South & Haida Gwaii & Channel Islands \\
\hline North & - & $0.479^{*}$ & $0.492^{*}$ & $0.681^{*}$ \\
South & 0.011 & - & $0.094^{*}$ & $0.228^{*}$ \\
Haida Gwaii & 0.013 & $0.038^{*}$ & - & $0.564^{*}$ \\
Channel Islands & $0.130^{*}$ & $0.091^{*}$ & $0.178^{*}$ & - \\
\hline
\end{tabular}

1 


\section{Table 4 (on next page)}

Table 4. Subspecies pairwise divergence statistics.

This table presents divergence statistics for pairwise subspecies comparisons calculated using ND2 mitochondrial DNA sequence ( $\Phi_{\mathrm{ST}}$ above diagonal) and microsatellite data ( $R_{\mathrm{ST}}$ below diagonal). Values followed by asterisks are significant after applying a Bonferroni correction $(p \leq 0.008)$. See Table S1 for the samples included in each population. 


\begin{tabular}{lcccc}
\hline & lutescens & orestera & celata & sordida \\
\hline lutescens & - & $0.126^{*}$ & $0.469^{*}$ & $0.232^{*}$ \\
orestera & $0.021^{*}$ & - & $0.258^{*}$ & $0.375^{*}$ \\
celata & 0.016 & $0.046^{*}$ & - & $0.786^{*}$ \\
sordida & $0.106^{*}$ & $0.105^{*}$ & $0.187^{*}$ & - \\
\hline
\end{tabular}

1

Peer) reviewing PDF | (2018:09:31580:2:0:NEW 27 Jun 2019) 


\section{Table 5 (on next page)}

Table 5. Variability of the microsatellite loci in the north, south, and island populations.

This table presents the variability of the ten microsatellite loci in each of the four Oreothlypis celata populations in the North-South population schema. We indicate the number of individuals genotyped for each locus, "N". Column "A" provides the number of alleles at each locus in each population, with the number of private alleles given in parentheses. We also provide estimated values of allelic richness " $\mathrm{R}_{s}$ ", observed heterozygosity " $\mathrm{H}_{0}$ ", expected heterozygosity " $\mathrm{H}_{\mathrm{E}}$ ", and the associated $p$-values for each locus in each population. No $p$ values were significant after Bonferroni correction $(p<0.005)$. 


\begin{tabular}{|c|c|c|c|c|c|c|c|}
\hline Population & Locus & $N$ & $\begin{array}{c}\text { A (Private } \\
\text { Alleles) }\end{array}$ & $\mathbf{R}_{\mathbf{S}}$ & $\mathbf{H}_{\mathbf{O}}$ & $\mathbf{H}_{\mathrm{E}}$ & $p$-val \\
\hline \multicolumn{8}{|l|}{ North } \\
\hline & Vce34 & 43 & $10(1)$ & 8.51 & 0.698 & 0.827 & 0.085 \\
\hline & Vce50 & 43 & 37 (4) & 24.14 & 0.953 & 0.966 & 0.738 \\
\hline & Vce70 & 42 & $4(0)$ & 3.66 & 0.452 & 0.555 & 0.177 \\
\hline & Vce102 & 42 & $12(3)$ & 9.664 & 0.738 & 0.836 & 0.223 \\
\hline & Vce103 & 42 & $8(0)$ & 7.011 & 0.571 & 0.640 & 0.059 \\
\hline & Vce109 & 42 & $10(1)$ & 8.331 & 0.833 & 0.833 & 0.381 \\
\hline & Vce116 & 42 & $10(2)$ & 8.146 & 0.786 & 0.839 & 0.331 \\
\hline & Vce128 & 42 & $18(0)$ & 14.43 & 0.857 & 0.924 & 0.211 \\
\hline & Vce167 & 43 & $23(4)$ & 17.00 & 0.814 & 0.915 & 0.097 \\
\hline & Vce179 & 43 & $8(0)$ & 6.869 & 0.860 & 0.788 & 0.190 \\
\hline \multicolumn{8}{|l|}{ South } \\
\hline & Vce34 & 94 & $10(0)$ & 7.428 & 0.798 & 0.804 & 0.633 \\
\hline & Vce50 & 93 & $42(7)$ & 21.90 & 0.946 & 0.962 & 0.029 \\
\hline & Vce70 & 94 & $5(0)$ & 3.711 & 0.500 & 0.571 & 0.643 \\
\hline & Vce102 & 94 & $13(3)$ & 9.119 & 0.766 & 0.827 & 0.250 \\
\hline & Vce103 & 94 & $12(3)$ & 6.884 & 0.574 & 0.634 & 0.067 \\
\hline & Vce109 & 94 & $14(3)$ & 8.691 & 0.840 & 0.810 & 0.070 \\
\hline & Vce116 & 94 & $10(1)$ & 7.471 & 0.830 & 0.813 & 0.829 \\
\hline & Vce128 & 94 & $20(0)$ & 13.31 & 0.883 & 0.892 & 0.141 \\
\hline & Vce167 & 94 & $28(6)$ & 17.08 & 0.872 & 0.914 & 0.569 \\
\hline & Vce179 & 94 & $11(2)$ & 7.593 & 0.840 & 0.779 & 0.424 \\
\hline \multicolumn{8}{|c|}{ Haida Gwaii } \\
\hline & Vce34 & 20 & $7(0)$ & 7.000 & 0.650 & 0.797 & 0.277 \\
\hline & Vce50 & 20 & $24(3)$ & 24.00 & 1.000 & 0.962 & 1.000 \\
\hline & Vce70 & 20 & $4(0)$ & 4.000 & 0.550 & 0.581 & 0.141 \\
\hline & Vce102 & 20 & $7(0)$ & 7.000 & 0.550 & 0.772 & 0.064 \\
\hline & Vce103 & 20 & $8(0)$ & 8.000 & 0.650 & 0.669 & 0.899 \\
\hline & Vce109 & 20 & $9(0)$ & 9.000 & 0.700 & 0.853 & 0.029 \\
\hline & Vce116 & 20 & $7(1)$ & 7.000 & 0.900 & 0.792 & 0.224 \\
\hline & Vce128 & 20 & $9(0)$ & 9.000 & 0.750 & 0.768 & 0.493 \\
\hline & Vce167 & 20 & $16(0)$ & 16.00 & 0.900 & 0.935 & 0.813 \\
\hline & Vce179 & 20 & $7(0)$ & 7.000 & 0.650 & 0.740 & 0.271 \\
\hline \multicolumn{8}{|c|}{ Channel Islands } \\
\hline & Vce34 & 30 & $9(0)$ & 8.308 & 0.700 & 0.779 & 0.364 \\
\hline & Vce50 & 30 & $23(2)$ & 19.18 & 0.900 & 0.945 & 0.562 \\
\hline & Vce70 & 30 & $3(0)$ & 2.893 & 0.500 & 0.505 & 0.725 \\
\hline & Vce102 & 30 & $7(0)$ & 6.549 & 0.800 & 0.802 & 0.375 \\
\hline & Vce103 & 30 & $2(0)$ & 2.000 & 0.467 & 0.364 & 0.295 \\
\hline & Vce109 & 30 & $8(0)$ & 7.678 & 0.833 & 0.829 & 0.650 \\
\hline & Vce116 & 30 & $8(0)$ & 7.409 & 0.700 & 0.789 & 0.144 \\
\hline & Vce128 & 29 & $14(1)$ & 11.85 & 0.724 & 0.704 & 0.467 \\
\hline & Vce167 & 29 & $15(0)$ & 13.82 & 0.655 & 0.902 & 0.006 \\
\hline & Vce179 & 30 & $7(0)$ & 6.549 & 0.833 & 0.775 & 0.820 \\
\hline
\end{tabular}

